\title{
FILOSOFÍA JURÍDICA LATINO AMERICANA EN EL SIGLO XXI. LA (RE)INSURGENCIA HISTÓRICA DEL DERECHO DE LOS POBRES Y LA NATURALEZA: EL IUSMATERIALISMO
}

\author{
Antonio Salamanca ${ }^{1}$
}

\begin{abstract}
Resumen:
Este artículo pretende contribuir en la respuesta a la pregunta: ¿cómo salirdel estado actual de enajenación e indigencia ideológico-jurídica en América Latina en el siglo XXI? En una primera parte se mapea la difusión actual de las dos grandes tradiciones jurídicas coloniales históricamente hegemónicas en el Continente: el iusnaturalismo y el iuspositivismo. En un segundo momento se identifica la pluralidad de pensamientos (filosofías-teorías) jurídicos críticos contrahegemónicos hoy en Latinoamérica. La última parte del artículo irrumpe apelando a la urgencia de empoderamiento, a la (re)insurgencia, del paradigma jurídico liberador propio de los pobres y de la naturaleza: el iusmaterialismo. Se indaga sobre sus principales postulados y posibilidades, develando en diálogo las limitaciones y complicidades ideológicas de las tradiciones iusnaturalistas e iuspositivistas, así como algunas carencias del postpositivismoen el pensamiento jurídico crítico. Metodológicamente, la investigación acoge el modo (perspectiva) ideológico-jurídico. La técnica fundamental es la bibliográfica. En particular, para el mapeo sesigue las obrasFilosofía del Derecho en Latinoamérica(2012), de Rodolfo Vázquez y Teoría Crítica del Derecho desde América Latina(2017), de A. C. Wolkmer.Para el aporte iusmaterialista se recurre fundamentalmente a nuestras obrasFilosofía de la Revolución (2008) yTeoría Socialista del Derecho (2011).
\end{abstract}

Palabras claves: Filosofía jurídica latinoamericana. Iusnaturalismo. Iuspositivismo. Pluralismo jurídico.Iusmaterialismo.Derechos de los pobres.Insurgencia jurídica.

\section{LATIN AMERICAN LEGAL PHILOSOPHY IN THE 21ST CENTURY. THE HISTORICAL (RE) INSURGENCY OF THE RIGHT OF THE POOR AND NATURE: IUSMATERIALISM}

\begin{abstract}
:
Thisarticleaimstocontributetotheanswertothequestion: howtogetoutofthecurrentstateofalienation and ideological-legal indigence in LatinAmerica in the 21st century? In thefirstpart, itismappedthecurrentdiffusionofthetwohistoricallydominant colonial hegemonic legal traditions in theContinent: the natural law and theiuspositivism. In a secondmoment, itisidentifiedtodaythepluralityofcounterhegemoniccritical legal thoughts (philosophies-theories) in Latin-America. Thelastpartofthearticle appeals totheurgencyofempowerment, tothe (re) insurgency, oftheliberating legal paradigmprop-ertothepoor and tonature: theiusmaterialism. Itinquiriesaboutitsmainpostulates and possibilities, revealing in dialogue thelimitations and ideologicalcomplicitiesoftheiusnaturalist and iuspositivisttraditions, as well as somelacksofthepostpositivism in critical legal thinking. Methodologically, theresearchwelcomestheideological-legal mode (perspective). The fundamental techniqueisthebibliography. In particular, forthemap-ping, wefollowtheworks Filosofía del Derecho en Latinoamérica (2012), by Rodolfo Váz-quez, and Teoría Crítica del Derecho desde América Latina (2017), by A. C. Wolkmer. Fortheiusmaterialistcontributionisusedmainlyourworks Filosofía de la Revolución (2008) and Teoría Socialista del Derecho (2011).
\end{abstract}

1. Profesor titular de Derecho, Instituto Altos Estudios Nacionales, Universidad Posgrado del Estado, Quito (Ecuador).E-mail: salamancantonio@hotmail.com. 
Keywords: Latin-American legal philosophy.Iusnaturalism.Iuspositivism.Legal pluralism.Iusmaterialism.Rightsofthepor.Legal insurgency.

\section{Introducción}

La praxis (la acción) de la vida de los seres humanos tiene una capacidad cognitiva. Ella posibilita la ideología. La capacidad cognitiva tiene un momento reflexivo-racional, que da lugar a lo que entendemos por filosofía-teoría científica. Las ideologías, como modos de aprehender cognitivamente el mundo, por la unidad con la capacidad ejecutiva y afectivade la praxis, son modos de conducirnos la existencia. Por ello, las ideologías que realmente se tienen — no las que se dice que se tienen — son las que movilizan nuestras acciones, aunque con el discurso de la boca prediquemos otras cosas. Salvo que se viva en la disociación cognitiva y se termine en la esquizofrenia, si uno no vive como piensa, acaba pensando como vive. Dicho esto, un trabajo sobre las ideologías jurídicas, como el presente, no es un ejercicio sobre discursos sin saliva, sobre opiniones sin implicaciones. Por el contrario, es una indagaciónen los giroscopios, en las constelaciones de ideas sobre las relaciones sociales de poder, sobre las brújulas cognitivas que mueven a las personas y los pueblos. La actividad cognitiva reflexivoracional explicativa nos permite el camino de la filosofía y de la teoría científica para juzgar los avances y errores de las diversas ideologías, filosofías y teorías científicas respecto a la verdad de la vida de los pueblos y la naturaleza. En definitiva, aquí tratamos sobre los circuitos ideológico-jurídicos integrados (chips) que mueven nuestros programas de vida personal y colectiva.

Los tiempos que vivimos en el siglo XXI, y los que vienen, están reclamando la (re)insurgencia histórica del derecho de los oprimidos, de los pobres y de la naturaleza. Los pueblos necesitan deshacerse ya del aparejo del derecho burgués que le han cinchado por doscientos años. Los pueblos están urgidos de volverse a sus más genuinas tradiciones jurídicas iusmaterialistas; caminar hacia el futuro mirando históricamente al pasado. Los pueblos latinoamericanos (y del mundo) necesitan empoderarse tomando el derecho en sus manos.

Para quienes asumen la fe en el mito de progreso de la ciencia capitalista, como señala Rodolfo Vázquez: “[r]esulta ya un lugar común afirmar que América La-

\begin{tabular}{|l|l|l|l|l|}
\cline { 2 - 5 } Q Qovista Dialectus & Ano 5 & n.13 & Agosto - Dezembro 2018 & p. 27 - 77 \\
\hline
\end{tabular}


tina ha sido una rezagada con relación a las tres revoluciones científico-tecnológicas modernas: se educa en el dogmatismo de la contrarreforma sin haber conocido la reforma; importa una concepción liberal e ilustrada del Estado sin una burguesía que la haya instrumentado; e incorpora el discurso de la globalización ignorando las profundas desigualdades ancestrales de nuestros pueblos" (Vázquez, 2012, p. 834). Sin embargo, viendo la historia desde el lugar de las víctimas, a América Latina más bien llegó muy pronto el sometimiento al dogmatismo de la contrarreforma, al liberalismo de la globalización colonial capitalista yal fetichismo de su derecho burgués. I. Wallerstein y E. Dussel nos recuerdan que el sistema mundo ideológico, económico, político y jurídico comienza con la Conquista en 1492.

En el ámbito concreto de la filosofía jurídica en el nuevo mundo, antes de la llegada de los ibéricos a las nuevas tierras con la cruz, la toga y la espada,algunos de estos pueblos eran hijos de la civilización de Caral (Perú), la primera ciudad-estado del Continente, con aproximadamente unos 5.000 años de antigüedad(Shady y Leyva, 2003). Por cierto, ¿cuántos textos de historia del derecho en Latinoamérica comienzan con Caral?, —utilizando la categoría de Pablo González Casanova, aún hoy el colonialismo interno es feroz — . Desde hace 12 mil años o más, desde la llegada de los primeros emigrantes, los pueblos de lo que llamaránAbya Yala tenían sus filosofías jurídica. Filosofías morales, políticas y jurídicas sin mediación escrita, consuetudinarias, plurales,y en gran medida descentralizadas.

Desde el siglo XV, con el llamado por E. Dussel "encubrimiento del otro", primero de los españoles y portugueses, se pone en marcha el sistema mundo jurídico en las tierras de América. En las carabelas de los cerebros ibéricos y sus relaciones sociales de poder se importa una filosofía jurídica que era hegemónica en el discurso legitimador europeo: el derecho natural (iusnaturalismo).Tres siglos más tarde, manchada con la sangre del holocausto de millones de indígenas del nuevo mundo y población esclava africana, en el siglo XVIII, una nueva clase social se hace hegemónica en las metrópolis imperiales y luego en las coloniales: la burguesía. Conquista el poder ideológico, político-institucional y jurídico en Europa y sus colonias. A pesar de que destrona a monarquías, aristocracias y clero apelando al iusnaturalismo, ya en la silla del

\begin{tabular}{|c|c|c|c|c|}
\cline { 2 - 5 } & Ano 5 & n.13 & Agosto-Dezembro 2018 & p. $27-77$ \\
\hline
\end{tabular}


poder engendra un nuevo paradigma de derecho, que desplegará desde el siglo XIX a lo largo y ancho del planeta. Esa constelación jurídica será bautizada como positivismo jurídico. En esencia no es sino el voluntarismo despótico medieval, y antiguo, pero más sofisticado. No se legitima ya en derechos naturales, que limita a los burgueses el ejercicio del poder - aunque, como hemos indicado, apelando a ellos se asentaron en el trono del despotismo_- Su legitimación abiertamente reside ahora en la voluntad de quien manda, de quien tiene el monopolio de la violencia coactiva en la sociedad: la nueva clase burguesa. Desde el siglo XIX, el positivismo jurídico va colonizando todos los espacios (legislación, universidades, facultades de derecho, operadores jurídicos, jueces, fiscales, abogados, policías, imaginario simbólico de los pueblos, etc.). En las dos últimas centurias, iusnaturalismo e iuspositivismo se han disputado los ámbitos de poder ideológico y social. Uno, el primero, en repliegue; otro, el positivismo jurídico, es ascenso y dominación imperial imparable.

Las facultades de derecho que pronto se crearán en las universidades, en términos generales desde entonces fueronun espacio fundamental de la dominación jurídica. Las han transustanciado en templos esotéricos de un sacerdocio que pretende administrar el derecho — como si el derecho no se produjera en los campos y las calles y no fuese administrado (empoderado) por las comunidades con su institucionalidad. Las materias de las carreras de derecho (mallas, programas) se dedican en gran parte a la glosa, a la exégesis de los oráculos del interés del capital convertido en ley. Disciplinas como la filosofía del derecho se han eliminado o reducido a filosofía positivista.Ello se ha debido, entre otras razones, a que se identificaba la filosofía jurídica con la disciplina del derecho natural; o a que la filosofía quedaba disuelta y superada por el estadio de desarrollo superior propio de la ciencia, de la teoría del derecho: la dogmática jurídica. A modo de ejemplos, como recoge R. Vázquez:“[e]n un tono categórico y crítico, no carente de realismo, M. Salas sostiene que «en Costa Rica - y me temo que en buena medida en Centroamérica - no existe realmente filosofía del derecho. [...] A tal extremo se ha llegado que, en muchas universidades, la asignatura ya se suprimió; es decir, forma parte de anaqueles históricos y de proyectos curriculares fallidos, o no existe del todo»" (Vázquez, 2012, p. 842). Por su parte, Manuel Atienza en su Manifiesto (2014) cons-

\begin{tabular}{|c|c|c|c|c|}
\cline { 2 - 5 } & Ano 5 & n.13 & Agosto-Dezembro 2018 & p. $27-77$ \\
\hline
\end{tabular}


tata que en aquellos países donde la filosofía del derecho mantiene o ha alcanzado "un lugar académicamente destacado" y "un buen número de cultivadores de la disciplina con un alto nivel de competencia "técnica”, “¿[c]ómo explicar, entonces, que la producción iusfilosófica se limite en buena medida a comentar o discutir ideas y teorías surgidas en otros ámbitos culturales y destinada también muchas veces a tratar con problemas característicos de esos otros ámbitos"(Atienza, 2017, p. 49).En Uruguay, por ejemplo, como en otros muchos países,la filosofía del derecho "se repliega a una labor orientada a servir de apoyo a la formación profesional de abogados y escribanos, adoptando posiciones eclécticas, de compromiso, sincretismo" (Vázquez, 2012, pp. 850-851).

Con la opresión creciente del "contraderecho" burgués, el fetichismo normativo del sistema jurídico del capital pretende hacer creer que en el planeta se avanza en la garantía de los derechos de los pueblos y la naturaleza. Se encubre la situación real de indigencia jurídica de las grandes mayorías al tiempo que, en términos globales, las relaciones “jurídicas" (contraderechos) que más se extienden son las propias de un estado absoluto, despótico y fascista. R. Vázquez se hace eco del sentir de E. Zaffaroni: "'[t]odo indica...que lejos de enfilarnos desde un Estado legal de derecho a uno constitucional, involucionamos, de nueva cuenta, hacia un Estado «decretal» de derecho” (Vázquez, 2012, p. 835). Para la vida de los pueblos y la naturaleza, lo que la realidad evidencia es que el sistema jurídico burgués, con su paradigma ideológico, con sus teorías y filosofías del derecho, ha fracasado en América Latina. R. Vázquez (2010, p. 837)acoge el diagnóstico de R. Gargarella:

Después de más de doscientos años de vida del constitucionalismo moderno, entendido éste a partir de sus rasgos básicos — la adopción de una declaración de derechos y de un sistema de «frenos y contrapesos»- no puede decirse del mismo que su funcionamiento haya sido exitoso, particularmente en una mayoría de países de América. Tal mayoría de países sigue viéndose afectada por sistemas políticamente inestables y económicamente muy desiguales; en donde las violaciones de derechos humanos son un hecho habitual; las ramas políticas del gobierno tienden a funcionar con independencia de cualquier reclamo ciudadano, mientras se encargan de moldear normas a medida de intereses privados; los tribunales aparecen como órganos de difícil acceso público, que tienden a decidir en favor de los poderosos, criminalizando a quienes protestan; y en donde el debate público (tanto en las campañas electorales como, especialmente, en los periodos que transcurren entre una elección y otra) destaca por la pobreza de su contenido. [...] Según entiendo, la gravedad

\begin{tabular}{|l|l|l|l|l|}
\cline { 2 - 5 } Q & Ano 5 & n.13 & Agosto - Dezembro 2018 & p. 27 - 77 \\
\hline
\end{tabular}


de las deficiencias institucionales en juego nos obligan a dejar de lado la idea según la cual lo que se requiere es «perfeccionar»o «pulir» algunos aspectos de dicho esquema. [...] existe urgencia por repensar las causas de lo que es, en definitiva, un fracaso institucional con consecuencias ya trágicas (Gargarella, 2010, pp. 7-8).

En definitiva, durante los últimos quinientos años, el silencio, la marginación y desvalorización recayó sobre las otras filosofías jurídicas originarias de América Latina; sobre sus horizontes jurídicos fundamentalmente praxeológicos, consuetudinarios, iusmaterialistas. Las dos grandes ideologías o tradiciones jurídicas importadas: iusnaturalismo, primero, y, positivismo, después,colonizaron las relaciones sociales de poder de los pueblos de nuestra América hasta el día de hoy.

A inicios del siglo XXI, la cosmovisión del derecho burgués lleva tiempo mostrando sus límites y haciendo aguas. No sale del laberinto de su escepticismo cognitivo, de su pretendida asepsia política, del voluntarismo.Ha perdido el giroscopio de la moral, de la ética. Reducido al mundo analítico fenoménico, subjetivo o intersubjetivo, de las mediaciones discursivas lingüísticas, no cuenta con una teoría de la acción integrada; una teoría que dé cuenta, que explique sin contradicciones, intercultural e interdisciplinarmente, la realidad jurídica, el hecho del derecho.

Conscientes algunos de estos problemas, en 2016 tuvo lugar el Primer Congreso de Filosofía del Derecho para el Mundo Latino, celebrado en Alicante (España). Dando continuidad a esa preocupación, creemos que puede resultar de utilidad presentar un mapeo actual de las tradiciones filosóficas y jurídicas hegemónicas en América Latina y sus resistencias contrahegemónicas. En esa tensión dialéctica ubicaremos la (re)insurgencia del paradigma histórico jurídico de los pueblos pobres y oprimidos: el iusmaterialismo. Tradición invisibilizada, ninguneada, mancillada y sometida.

\section{Las filosofías-teorías jurídicas hegemónicas en América Latina en el siglo XXI}

Caben diversas clasificaciones de las principales teorías y filosofías jurídicas hegemónicas en América Latina. En el mapeo propuesto seguiremos los trabajos de A. E. Pérez Luño (2007) — que desarrollamos en La investigación jurídica intercultural e interdisciplinar (2015)_, Rodolfo Vázquez (2012) yA. C. Wolkmer (2017). Todas ellas coinciden en asumir implícitamente que la filosofía jurídica en nuestra Amé-

\begin{tabular}{|l|l|l|l|l|}
\cline { 2 - 5 } Q & Ano 5 & n.13 & Agosto - Dezembro 2018 & p. 27 - 77 \\
\hline
\end{tabular}


rica comienza con los primeros "textos escritos" de juristas "profesionales" correspondiente a los últimos 500 años. Ello implica borrar de un plumazo la etapa prehispánica de pluralismo jurídico consuetudinario, al menos 12.000 años de filosofía jurídica no escrita y "no profesional".

A. C. Wolmer (2017) hace una clasificación según tres momentos de la historicidad jurídica en América Latina: 1) la cultura jurídica durante la conquista y la colonización;2) en la época de la post-independencia; 3 ) en la contemporaneidad tardía: escenarios incompletos (p. 230). En la primera etapa (ss. XV-XVIII) seevidencia un pluralismo legislativo de la metrópoli y entre esta y las colonias. A su juicio, se caracterizó por "un derecho eurocéntrico difuso, influenciado por los sistemas románicos, canónicos y germánicos que se secularizó y unificó durante el reinado de los Reyes Católicos y se manifestó bajo la forma de un pluralismo legislativo instituido (...)” (p. 230). Expresión de ello es la influencia jurídica de las Siete Partidas (1256-1265), el Ordenamiento de Alcalá de Henares (1648), los Fueros Municipales, Fueros Reales, Leyes de Toro, Leyes de Indias; así como las Ordenanzas Reales (Alfonsinas y, Manuelinas y Filipinas) en la colonización lusitana. Como contribuciones al pluralismo crítico desde el humanismo cristiano recoge los aportes en el Nuevo Mundo de Alonso de la Vera Cruz, Vasco de Quiroga, Antonio de Montesinos, Bartolomé de las Casas; y, en la península: Francisco Vitoria, Francisco Suárez, Domingo de Soto (pp. 230-231).

La segunda etapa,la post-independencia (s. XIX), según el autor, se caracteriza por las influencias jurídicasdel liberalismo, el positivismo, formalismo, el naturalismo, que se resiste a ser marginado, y el eclecticismo. Ejemplo de ello son los trabajos de Augusto Teixeira de Freitas (Brasil), Andrés Bello (Chile), Dalmacio Vélez Sarsfield y J. B. Alberdi (Argentina) (p. 236).

La tercera etapa son los escenarios inacabados de la contemporaneidad tardía (s. XX-hasta hoy). A su juicio, desde el siglo XX en América Latina los paradigmas jurídicos reproducen los de la modernidad eurocéntrica, "una tradición teórico-metafísica dividida entre idealistas y formalistas". El autor distingue tres familias jurídicas: a) naturalista, donde incluye neotomismo, racionalismo e historicismo. A modo de ejemplo, en Uruguay: J.

\begin{tabular}{|l|l|l|l|l|}
\cline { 2 - 5 } Q Qovista Dialectus & Ano 5 & n.13 & Agosto - Dezembro 2018 & p. 27 - 77 \\
\hline
\end{tabular}


Llambías de Azevedo; Argentina: Tomás Casares; México: Mauricio Beuchot; Brasil: Alceu de A. Lima; André Franco Montoro; b) positivismo, en el que ubica normativistas kelsenianos, analíticos y formalistas lógicos. De esta tradición son muestra, en México: Javier Esquivel Pérez, R. Tamayo Salmorán y Eduardo García Máynez; Chile: Agustín Squella; Colombia: Luis Villar Borda; Perú: Francisco Miró Quesada; Argentina: Ambrosio Gioja; Genaro R. Carrió, E. Garzón Valdés, Roberto J. Vernego, Carlos Nino, Carlos E. Alchourrón; Brasil: Pontes de Miranda); y c) eclecticismo, que acoge expresiones jurídicas existencialistas, fenomenológicas, vitalistas egológicas ytridimensionalistas). De esta tercera tradición tenemos ejemplos en Chile: J. Hübner Gallo; Argentina: Carlos Cossio y Werner Goldschmidt; Brasil: A. L Machado Neto y Miguel Reale(Wolkmer, 2017, pp. 239240).

Un segundo grupo de sistematizaciones más ideológico-jurídicas son las presentadas por E. Pérez Luño (2007) y Rodolfo Vázquez (2011). En ellas se sigue olvidando que la ideología hegemónica más extendida en el territorio y el tiempo ha sido la praxis jurídica pluralista. Con esta advertencia y completando los aportes de ambos autores, se puede mapear las siguientes ideologías jurídicas que han hegemonizado América Latina desde la Conquista: el iusnaturalismo y el iuspositivismo.

$\left(1^{\circ}\right)$ El iusnaturalismo. Como hemos indicado, la filosofía y teoría jurídica iusnaturalista llegó al Continente americano con la Conquista ibérica en 1492. Llegó de la mano de los conquistadores, de los frailes y sacerdotes, de los jurisconsultos. Se institucionalizó pronto con la fundación de las primeras universidades, con sus facultades de derecho y la enseñanza del derecho canónico. En términos generales, este modo de ver el mundo jurídico se asienta en una concepción teológica o no científica de la naturaleza humana (de lo que denominainstintos, pasiones, alma, espíritu, etc.). Fundamento que, se afirma, es susceptible de ser descubierto por el conocimiento humano, frecuentemente por deducción racional. Sostiene que existen unos derechos, llamados naturales, que son innatos a la naturaleza del homo sapiens sapiens. Los derechos son facultades, expectativas innatas. Vienen con el nacimiento de cada persona. Estos derechos (v. gr. derecho a la vida, a la sociabilidad, a la seguridad, etc.) son el contenido de la dignidad del ser humano (a imagen y semejanza de Dios, en la expresión teocrática del iusnaturalismo), y/o descubiertos por la razón.

\begin{tabular}{|c|c|c|c|c|}
\cline { 2 - 5 } & Ano 5 & n.13 & Agosto-Dezembro 2018 & p. $27-77$ \\
\hline
\end{tabular}


En el Occidente europeo, este paradigma jurídico se fue haciendo hegemónico desde la Antigüedad en el discurso de legitimación del poder político y modo de ver el mundo, manteniendo su dominio hasta el siglo XIX. La Iglesia católica en sus dos mil años de existencia acogió esta filosofía jurídica como propia y la convirtió en un medio fundamental para su expansión. Desde el siglo XIX ha ido perdiendo influencia ante el emergente iuspositivismo.La pérdida de influencia en esta época no significa que haya desaparecido. A modo de ejemplo, en un rápido recorrido,en el siglo XX y lo que llevamos del siglo XXI encontramos una pluralidad de propuestas iusnaturalistas. Siguiendo lo expuesto en La investigación Jurídica Intercultural e Interdisciplinar(Salamanca 2015), en Europa han sido y son ilustrativas las teorías del Derecho natural de contenido variable, de R. Stammler; el Derecho Natural de contenido progresivo, de G. Renard; la teoría del iusnaturalismo historicista, de G. Fassò y la ontofenomenología del Derecho, de Sergio Cotta, continuada en Italia, en su perspectiva existencialista, por sus discípulos: Bruno Romano, Francesco D’Agostino y Bruno Montanari (pp.83).

A la hora de una sistematización de las diversas teorías jurídicas recientes nacidas en el seno de la tradición iusnaturalista resulta útil el criterio de clasificación del profesorA. E. Pérez Luño. El autor divide el iusnaturalismo en dos grandes familias o tradiciones: $1^{\circ}$ ) A la primera le llamaontológica, dogmática o radical. En este grupo engloba la producción de autores comoAmbrosetti, Charmont, Corts Grau, Cotta, Elías de Tejada, Fernández Galiano, Finnis, Galán, Lachance, Luño Peña, Maritain, Messner, Puy, el último Radbruch, Villey. $2^{\circ}$ ) La segunda tradición es la deontológica, crítica o moderada. Agrupa en este camino la obra de Bloch, Del Vecchio, Dworkin, Fuller, Fassò, LegazLacambra, RecasénsSiches, Stammler, Truyoly Serra, Welzel y Wolf (pp.83).

La ideologíaiusnaturalista europeaextendió su influencia y colonizóAmérica Latina.Como hemos indicado, este fue el paradigma filosófico jurídico hegemónico en el discurso legitimador de los conquistadores desde el siglo XV hasta el siglo XIX aunque en algunos países su hegemonía resistió hasta inicios del siglo XX- Decimos en el discurso, porque en la práctica, el voluntarismo jurídico ha sido siempre el denominador común, sea del estado esclavista antiguo, del estado feudal europeo, de la monarquía despótica, del estado de encomienda, mita, obrajes y reducciones, de los lla-

\begin{tabular}{|c|c|c|c|c|}
\cline { 2 - 5 } & Ano 5 & n.13 & Agosto-Dezembro 2018 & p. $27-77$ \\
\hline
\end{tabular}




\section{FILOSOFÍA JURÍDICA LATINO AMERICANA EN EL SIGLO XXI...}

Antonio Salamanca

mados estados de derecho liberales burgueses centrales y su colonias periféricas, o de los estados constitucionales de derecho en nuestros días.

En América Latina, A. E. Pérez Luño diferencia dos orientaciones iusnaturalistas principales: $1^{\mathrm{a}}$ ) Iusnaturalismo racionalista (v.gr. el uruguayo Juan LLambías de Azevedo, los mexicanos Rafael Preciado Hernández y Guillermo Héctor Rodríguez); 2 ${ }^{a}$ ) Iusnaturalismo neotomista(los argentinos Avelino Manuel Quintas y Tomás Casares, los mexicanos Mauricio Beuchot y Jesús Antonio de la Torre Rangel, el brasileño AmiltonBueno de Carvalho, el peruano Carlos Alberto Torres Caro). Por su parte, Rodolfo Vázquez (2012)distingue el iusnaturalismo racionalista o teológico (escolático tomista, católico), analógico e histórico analógico. En Colombia, por ejemplo, la influencia iusnaturalista se puede identificar en sus textos constitucionales, llegando hasta la constitución liberal laica colombiana de 1991(Vázquez, 2012, p. 839). En Chile, influencias del iusnaturalismo tomista lo encontramos en la obra de C. Orrego, o con influencia de la relectura de la razón práctica de J. Finnis, en J. García Huidobro; (Vázquez, 2012, p. 844). En México, han cultivado este paradigma, entre otros muchos, autores relevantes como Preciado Hernández, M. Villoro, A. Gómez Robledo, H. González Uribe y E. González Morfín, J. Ruiz de Santiago. Como expresión del iusnaturalismo hermenéutico analógico puede encontrarse la obra de J. Saldaña, o la obra de M. Beuchot, Diversidad y diálogo intercultural (2018); y del iusnaturalismo histórico analógico (liberador) la obra de J. de La Torre Rangel, Hermenéutica analógica: derecho y derechos humanos (2004), El derecho que nace del pueblo (1986). En Perú, con sus variantes, el iusmaterialismo seráel paradigma hegemónico hasta mediados del siglo XX (Vázquez, 2012, pp. 846; 848).

$\left(2^{\circ}\right)$ Eliuspositivismo. El positivismo jurídico es un paradigma, una constelación de filosofías-teorías jurídicas, que entre sus principales postulados comparten, en mayor o menor grado, el escepticismo cognitivo respecto de la realidad, en general, y respecto de la realidad moral, en particular. Heredero de D. Hume, la "realidad" es creación del sujeto o de la intersubjetividad. Cree en el dogma de la falacia naturalista: del ser no se puede obtener el deber ser. El deber ser es fruto de la voluntad del sujeto o de la intersubjetividad. Para sus adeptos, el derecho tiene como fuente última de legi-

\begin{tabular}{|l|l|l|l|l|}
\cline { 2 - 5 } Q Qovista Dialectus & Ano 5 & n.13 & Agosto - Dezembro 2018 & p. 27 - 77 \\
\hline
\end{tabular}


timidad a la voluntad de quien detenta la hegemonía del poder (voluntarismo jurídico). El derecho es la voluntad "puesta" por quien detenta el monopolio de la violencia del poder. Voluntad sacralizada en textos normativos que generan obediencia por la amenaza del uso de la violencia en la sanción. El derecho es un sistema de intereses, deseos o demandas sociales acordados o coordinados mediante el diálogo de algunos, consenso, pactos o contratos, impuestos por la voluntad de quien detenta el poder.

El positivismo jurídico acelera en el siglo XIX el proceso de convertirse en la ideología hegemónica en los aparatos de poder (instituciones políticas, facultades de derecho, etc.). Lo consiguió en el siglo XX, y hoy sigue profundizando su dominio en todo el planeta (Salamanca, 2017). Este horizonte o modo de ver las relaciones jurídicas ha dado lugar a una pluralidad de filosofías-teorías. Caben diversas clasificaciones según el énfasis que se ponga en algunos u otros criterios. A. E. Pérez Luño (2007) distingue dos grandes familias de filosofías-teorías positivistas: $1^{\circ}$ ) Positivismo normativista: radical (Kelsen); moderado (Hart); $2^{\circ}$ ) Postpositivismo: positivismo jurídico institucional (Neil MacCormik, Ota Weinberg); positivismo crítico (Ferrajoli, Scarpelli); postpositivismo jurídico estructural (Friedrich Müller); positivistas jurídicos 'positivos y negativos' (Coleman), e 'incluyentes y excluyentes' (Waluchow) (Salamanca, 2015: 85).

En América Latina, en una aproximación general se encuentran dos grandes corrientes dentro del positivismo jurídico: $1^{\text {a) }}$ El positivismo normativista kelseniano (los mexicanos Javier Esquivel, Ulises Shmill, Rolando Tamayo Salmorán; el colombiano Luis Villar Borda; los chilenos Agustín Squella y Nelson Reyes; los peruanos Domingo García Belaunde y José Palomino Manchego; $2^{\mathrm{a}}$ ) El positivismo analítico (los argentinos Ambrosio Gioja, Genaro Carrió, Ernesto Garzón Valdés, Alchourrón, Bulygin, Farrel, Guibourg, Martino, Rabossi, Vernengo, Warat) (Salamanca, 2015: 85).

La clasificación de Rodolfo Vázquez (2012)diferencia los siguientes desarrollos: el positivismo jurídico analítico, normativista, neokantiano, discursivo,hermenéutico interpretativo, argumentativo, sociológico y filosófico-moral positivista.

El positivismo jurídico analíticoha tenido una amplia difusión por todo el continente latinoamericano. A modo de ejemplo, ha sido cultivado, entre otros lugares

\begin{tabular}{|l|l|l|l|l|}
\cline { 2 - 5 } Q Qovista Dialectus & Ano 5 & n.13 & Agosto - Dezembro 2018 & p. 27 - 77 \\
\hline
\end{tabular}


y autores, porG.GonzálezSolano, en Costa Rica (E. P. Haba, de origen uruguayo, es una de las figuras relevantes con postulados comunes a muchos positivistas: el escepticismo epistemológico, la orientación analítica y el individualismo empírico). En Méxi-

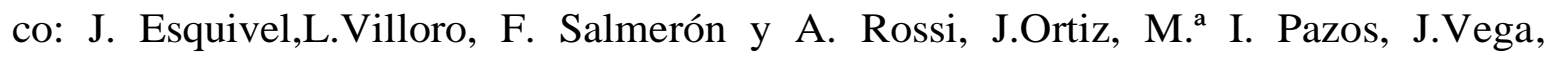
J.Cerdio, A.Rodríguez Tirado, J.GarcíaRebolledoyA.Oñate. En Argentina: R.Vernengo, E.BuLygin, C.Alchourrón, E.Garzón Valdés y C. Santiago Nino. El positivismo analítico (y lógico jurídico)se ha trabajado enMéxico. Ejemplo de ello son las obras: Lógica del raciocinio jurídico (1964), La definición del derecho. Ensayo de perspectivismo jurídico (1960),Lógica del concepto jurídico (1959), Lógica del juicio jurídico (1955),de E. García Maynez; en Perú, la obra Principios fundamentales de lógica jurídica(1956) y demás trabajos de F. Miró Quesada muestran la dimensión descriptivo-prescriptiva de la norma. En Uruguay, E. J. Coutureindaga sobre el lenguaje jurídico ylógica jurídica.

La variante normativista, de inspiración kelseniana, ha tenido acogidaen Colombia, entre otros,con el trabajo deL. E. NietoArtet. En Chile, A. Bascuñán y A. Squella. La obra de este es un claro ejemploNorberto Bobbio: Un hombre fiero y justo (2005). En Uruguay,la influencia kelseniana se encuentra en J. L. Moreno.

La variante positivista neokantiana ha encontrado eco en Méxicoen la obra de Héctor Rodríguez,L. Azuara, F. Vallado Berrón, U. Schmill, A. Pérez Carrillo y R. Tamayo y Salmorán.

El desarrolloprocedimimental-discursivo, en Colombia evidencia la influencia de la teoría discursiva de J. Habermas. G. Hoyos Vázquez, publicó, con A. Uribe, Convergencia entre ética y política; O. Mejía Quintana Derecho, legitimidad y democracia deliberativa y Teoría política, democracia radical y filosofía del derecho. En Perú, cabe mencionarla obra de D. Sobrevilla, abordada desde un positivismo incluyente.

El positivismo hermenéutico asume los aportes de las obras de R. Dworkin Toulmin, Perelman, MacCormick, Aarnio, Peczenik y Atienza en la interpretación del derecho. En Colombia, ejemplo de estason los trabajos de R. Arango, ¿Hay respuestas correctas en el derecho?(1999) y Derechos humanos como límites a la democracia (2008). En Uruguay,el trabajo hermenéutico de H. Malherbe se inspira en la dialéctica

\begin{tabular}{|c|c|c|c|c|}
\cline { 2 - 5 } & Ano 5 & n.13 & Agosto-Dezembro 2018 & p. $27-77$ \\
\hline
\end{tabular}


y la semiótica; Ó. Sarlo desarrolla su positivismo jurídico crítico apoyado en la hermenéutica gadameriana y el análisis del lenguaje, entre otras perspectivas. En cuanto a la interpretación judicial, a modo de ejemplo, es de resaltar en Colombia la publicación de la obra Interpretación judicial (2003) de R. Uprimny Yepes y A. Abel Rodríguez. En Perú, esta orientación aparece en la obra Ratio interpretandi. Ensayo de Hermenéutica Jurídica(2000), de F. Miró Quesada.

La variante del positivismo jurídico argumentativo, en Colombia, refleja la influencia de la orientación positivista jurídica trabajada, entre otros, por R. Alexis.Es el caso de la obra de R. Arango, El concepto de derechos sociales fundamentales. También en las contribuciones deC. Bernal Pulido y G. Lopera. En México, en un horizonte raciovoluntarista y culturalista se ubica los aportes de RecasénsSiches, Experiencia jurídica, naturaleza de la cosa y lógica "razonable”. Asimismo, en perspectiva análítico argumentativa se integran trabajos deR. Vázquez, A. Rentería, J. Cárdenas, J. A. Cruz Parcero, M. CarBonell y P. SaLazar Ugarte. En Venezuela, influidos por la teoría de la argumentación, tenemos los aportes de R. Pérez Perdomo. Asimismo, el discurso jurídico se ha abordado desde la semiosis de los signos y discursivos en el ámbito legislativo y judicial en la obra de R. Carrión.

La variante positivista del análisis económico del derechoha sido explorada, entre otros, en la obra de A. Roemer, en México; yen el trabajo de A. Bullard, Perú.

El positivismo jurídico axiológico, con influencia de J. Rawl, entre otros, ha sido recibido en Colombia en la obra John B. Rawls: El hombre y su legado intelectual, de L. García Jaramillo. En Chile, enRawls: el problema de la realidad y la justificación de la filosofía política, de C. Peña o en La prioridad del derecho sobreel bien en la Teoríade la justicia de John Rawls, de P. Ruiz Tagle. Asimismo es importante indicar la recepción del formalismo axiológico y voluntarista en Chile, en la obra Filosofía del derecho de J. Millas.

Compartimos la clasificación que hacen A. E. Pérez Luño y R. Vázquez de las ideologías jurídicas en América Latina en dos grandes tradiciones con sus variantes internas: iusnaturalismo e iuspositivismo. Sin embargo,como propusimos en La investigación jurídica intercultural e interdisciplinar (2015), creemos que puede resultar de utilidad

\begin{tabular}{|l|l|l|l|l|}
\cline { 2 - 5 } Q & Ano 5 & n.13 & Agosto - Dezembro 2018 & p. 27 - 77 \\
\hline
\end{tabular}


completar la clasificación de las familias del positivismo jurídico, a su vez, en dos grandes grupos: el iusvoluntarisma y eliusocio-constructivista. Asimismo, dentro de la familia iusvoluntaristapuede ayudar diferencia la variante deliusmarxismo supraestructural.Con relación a la primera sugerencia, en el referido artículo se ubicaban los siguientes grupos de trabajos bajo el paraguas del iusocio-constructivismo (funcional o crítico), que tendrán su influencia en Latinoamérica:

En la orientación iusocio-constructivista, arrancando solo desde el siglo XX, podemos identificar una diversidad de teorías dentro del horizonte de este paradigma: las teorías institucionalistas del Derecho, de M. Hauriou y Santi Romano; el realismo estadounidense, de O. W. Holmes, J. Frank, K. Llewellyn; el realismo escandinavo, de A. Hägerström, K. Olivecrona, A. Ross; la teoría general de las funciones, de G. Gavazzi; el funcionalismo sociológico de N. Bobbio; el contractualismo formalista, de J. Rawls; las teorías de la argumentaciónjurídica, de T. Viehweg, Ch. Perelman, R. Alexy, N. MacCormick, A. A. Arnio, A. Peczenik y J. Wróblewski; la teoría de la interpretación jurídica, de R. Dworkin; el sociologismo jurídico, de E. Ehrlich, R. Pound, P. Selznick, H.D. Lasswell, M.S. McDougal y R. Unger; la autopoisis jurídica, de N. Luhmann y G. Toubner; la praxis de libertad comunicativa, de J. Habermas; la teoría hermenéutica jurídica, de G. Zaccaria, y F. Viola; la teoría analítica lógicoformaldel derecho como sistema normativo, de C. Alchourron y E. Bulygin; la teoría del derecho analítica del lenguaje ordinario, de los argentinos Ambrosio Gioja, Genaro Carrió, Ernesto Garzón Valdés, Alchourrón, Bulygin, Farrel, Guibourg, Martino, Rabossi, Vernengo, Warat, C. S. Nino; las teorías críticas del Derecho, del movimiento estadounidense Critical Legal Studies (Salamanca, 2015, p. 84).

En América Latina, dentro del paradigma socio-contractualista crítico cabe diferenciar varias tendencias: $1^{\mathrm{a}}$ ) Derecho Alternativo y Pluralismo Jurídico (Luiz Fernando Coelho y Antonio Carlos Wolkmer); 2 $2^{\mathrm{a}}$ ) Sociología jurídica crítica (Bergalli, Correas, Pérez Perdomo, Malem); $3^{\mathrm{a}}$ ) El institucionalismo jurídico (el chileno Jorge Hübner Gallo, el argentino Carlos Cossio) (Salamanca, 2015, p. 84).

Por último, el positivismo jurídico (burgués) no es ciertamente la única expresión del iusvoluntarismo. También pertenece a esa familia el iusmarxismosupraestructrual, que tendrá su influencia en el pensamiento jurídico crítico de América Latina "[e]l iusmarxismo supraestructural y/o crítico es una teoría dentro del horizonte voluntarista, que aún tiene su vigencia. Las primeras teorías marxistas del derecho tomaron tres direcciones: $1^{\text {a }}$ La afirmación del condicionamiento económico del derecho (Kautsky y K. Renner). 2a La reducción del Derecho al voluntarismo político de la clase dominante (Vichinsky). $3^{\mathrm{a}}$ La reducción socioeconómica del derecho (Stucka y Pashukanis)(Salamanca, 2015, p. 85).

\begin{tabular}{|l|l|l|l|l|}
\cline { 2 - 5 } Qevista Dialectus & Ano 5 & n.13 & Agosto - Dezembro 2018 & p. 27 - 77 \\
\hline
\end{tabular}




\section{FILOSOFÍA JURÍDICA LATINO AMERICANA EN EL SIGLO XXI...}

Antonio Salamanca

Ahora bien, como hemos señalado arriba, la crisis y agotamiento del positivismo jurídico como paradigma hegemónico, con todos sus aportes y sus limitaciones se expresa en las críticas que surgen desde diversas disciplinas y ámbitos del derecho: la sociología jurídica, el neoconstitucionalismo, el análisis feminista del derecho, el análisis literario del derecho, el pluralismojurídico, la teoría crítica del derecho, etc.

M. Atienza (2017) están proponiendo la necesidad de un nuevo paradigma jurídico que denomina como "postpositivismo". A su juicio, pertenecerían a esta familia Dworkin, Alexy, Nino o MacCormick. Para el caso particular del constitucionalismo latinoamericano, él propone un constitucionalismo postpositivista. (Atienza, 2017, p. 11). El autor sitúa los orígenes recientes de esta propuesta postpositivista en la obra de Rudolf von Ihering.En su contenido:

[e]l postpositivimo no significa por ello la vuelta al Derecho natural, no niega el carácter "artificial", social e histórico del Derecho (esa vendría a ser, de acuerdo con González Vicén, la tesis central de todas las teorías iuspositivista: concebir el Derecho como una realidad social e histórica), pero sí la tesis de la separación metodológica o conceptual entre el Derecho y la moral; mejor aún, no niega que desde ciertas perspectivas sea posible (necesario) distinguir entre el Derecho y la moral, pero insiste en que esa separación no puede verse en términos dicotómicos, o sea, entre el Derecho y la moral hay tanto separación como continuidad: son "conceptos conjugados"(Atienza, 2017, p. 10).

\section{La filosofía jurídica crítica en América Latina en el siglo XXI}

La filosofía jurídica crítica práctica en América Latina ha sido una constante de los pueblos originarios desde su llegada anuestra América. La filosofía jurídica crítica en estas tierras fue fundamentalmente consuetudinaria, sin mediación escrita - y aún lo sigue siendo hoy-. El carácter revolucionario de esa filosofía jurídica quedó evidenciado con el combate y resistencia de muchos de los pueblos frente a los imperios regionales ( $v . g r$. azteca, inca, etc.) y ante la llega del sistema mundo de dominación, con la Conquista. Esta filosofía jurídica crítica es la "tradición madre" de las filosofías jurídicas críticaslatinoamericanas. Sus principales cultivadores han sido (también en número) los pueblos, en el anonimato de muchos de sus integrantes. Se ha hecho y hace en los campos, en las encomiendas, en las mitas, en los huasipungos, en los obrajes, en las reducciones, en las minas, en los barrios, en las calles, en las comunidades, y, relativamente poco, en los templos universita-

\begin{tabular}{|c|c|c|c|c|}
\hline Q Rovista Dialectus & Ano 5 & n.13 & Agosto - Dezembro 2018 & p. $27-77$ \\
\hline
\end{tabular}


rios. Es una filosofía de la praxis jurídica histórica, desfetichizadora de la mediación del texto sagrado de la ley. La praxis histórica de liberación es la fuente primera, el lugar epistemológico que "hace" y "da" verdad jurídica. Es el fontanal, el pozo de sabiduría jurídica con frecuencia invisibilizado, no estudiado, despreciado, ninguneado y criminalizado. Si queremos adentrarnos en las filosofías y teorías jurídicas críticas de este Continente es clave no olvidar este hecho de hechos (hecho mayor).

Para la presentación del mapeo de algunas de las filosofías-teorías jurídicas críticas en América Latina, seguimos la reciente obra de A. C. Wolkmer, Teoría Crítica del Derecho desde América Latina (2017). Si el panorama que nos ofrece el autor lo vemos con la clave expuesta en el párrafo anterior, encontraremos que: a) el pensamiento jurídico crítico en América Latina recogido en la obra tiene una fuerte circunscripción a la producción en los templos universitarios. A pesar de ello, están presentes propuestas que desafían estas limitaciones y apuntan a nuevos horizontes, como el "derecho que nace del pueblo" en la vida y obras de Jesús Antonio de La Torre Rangel (México), o“el derecho que nace de las calles y barrios", en la obra de Boaventura de Sousa Santos (Portugal, Brasil, Bolivia, Ecuador); b) el panorama del pensamiento jurídico crítico pareciera que comienza a finales del siglo XX con la influencia crítica europea. La desconexión histórica con la línea madre del pensamiento jurídico crítico de la colonia y prehispánico es llamativa (es una tarea pendiente para la filosofía jurídica crítica). A pesar de ello, se recogen propuestas que buscan la conexión con La tradición hispanoamericana de derechos humanos como es el caso de la obra con ese título de Alejandro Rosillo (México, 2012)). Con todo, el texto es un excelente trabajo para dibujar el atlas de lo que se produce hoy en América Latina en filosofía y teoría jurídica crítica, como decimos, fundamentalmente en los templos universitarios. Si estos tienen un papel ideológico fundamental para la dominación, también pueden serlo para la filosofía jurídica crítica emancipadora.

Sin embargo, es importante estar claros que esta filosofía contrahegemónica, dentro de los templos académicos, es hoy marginal, periférica y limitada en la articulación regional. El pensamiento jurídico crítico hoy no es hegemónico ni en América Latina ni en el resto del mundo. Es periférico, silenciado y de resistencia muchas veces. Esto hay que

\begin{tabular}{|c|c|c|c|c|}
\cline { 2 - 5 } & Ano 5 & n.13 & Agosto-Dezembro 2018 & p. $27-77$ \\
\hline
\end{tabular}


tenerlo en cuenta cuando nos acercamos a la obra de A. C. Wolkmer. El panorama que nos presenta es muy rico, no homogéneo, lleno de matices, esperanzador sin duda. Sin embargo, la exhaustividad de su trabajo no debe llevar a la idea de que es la conciencia jurídica mayoritaria en los pueblos ni la filosofía y teoría jurídica que se enseñamayormente en las facultades de derecho de la Universidades. Lo que domina y sigue creciendo es el dominiodel positivismo jurídico como, paradigma con las múltiples variantes de sus familias. El estado general de los pueblos es de indigencia jurídica y de enajenación de la conciencia del sus derechos. Una ideología jurídica, la de la clase burguesa, ha colonizado las vidas de los pueblos.

Según A. C. Wolkmer, en América Latina el pensamiento jurídico crítico del siglo XXI se está ocupando de problemáticas como las prácticas alternativas del derecho, derechos humanos, asesoría jurídica popular, pluralismo legal indígena, justicia comunitaria, Estado plurinacional y constitucionalismo andino, etc. (Wolkmer, 2017, p. 93). A su juicio, el acercamiento crítico a las referidas problemáticas le ha sido posible por la influencia de dos tradiciones jurídicas críticas: el Critical Legal Studies (estadounidense), el Uso Alternativo del Derecho y la Asociación Crítica del Derecho (europea).

Una primera tradición — en orden expositivo — es la crítica jurídica estadounidense. Las tendencias críticas del derecho en Estados Unidos tienen una articulación relevante con la fundación en 1977, en la Universidad de Wisconsin, del movimiento Critical Legal Studies. En su origen está un grupo interdisciplinar de profesores, vinculado algunos de ellos a la Law and SocietyAssociation . La ideología del movimiento es de izquierdas. La crítica al derecho es fundamentalmente histórico-ideológica. El movimiento jurídico crítico tiene sus inspiraciones en: la fenomenología, el historicismo (E. P. Thompson), el estructuralismo francés (M. Foucault), neomarxismo (A. Gramsci, H. Habermas, Offe). Se concibe al derecho como una supraestructura relativamente autónoma que cumple funciones ideológicas (C. Summer), de legitimación (H. Hayde), y para la construcción de una fuerza hegemónica (F. Genovese). Como autores fundamentales de este movimiento A. C. Wolkmer identifica a: Morton Horwitz, Duncan Kennedy, Mark Tushner, Karl Klare, Robert Gordon, Peter Gabel, Mark Kelman, Richard Abel, Thomas Heller, David Trubek, William Simon, Roberto Mangabeira Unger. Desde los años 1980, como otra expresión de la crítica y resis-

\begin{tabular}{|c|c|c|c|c|}
\cline { 2 - 5 } & Ano 5 & n.13 & Agosto-Dezembro 2018 & p. $27-77$ \\
\hline
\end{tabular}


tencia al paradigma jurídico hegemónico, la crítica al positivismo jurídico y al liberalismo utilitalista se va a concretar en propuestas demodelos normativos, de luchas por el acceso a la justicia distributiva, el reconocimiento de las diferencias, del feminismo y la raza, de la identidad y la igualdad, de la democracia deliberativa, de la subjetividad y colonialidad. Testimonio de ello son los trabajos de Iris Marion Young, Nancy Fraser, SeylaBenhabid, Judith Butler, Jean Cohen y Andrew Arato (pp. 58-62).

La segunda tradición identificada por A. C. Wolkmer es el pensamiento crítico europeo. El autorencuentra influencias de la filosofía-teoría crítica social europea, particularmente de la Escuela de Fráncfort. Las filosofías críticas de autores como Max Horkheimer, Theodor Adorno, Walter Benjamin, Herbert Marcuse y Jürgen Habermas trasmiten los aportes de los maestros de la sospecha, K. Marx, F. Nietzsche y S. Freud. A esta constelación de pensamientos críticos les une la emancipación humana como horizonte; emancipaciónde todo estado de reducción de la humanidad a cosa (reificación), aunque no necesariamente debe ser elproyecto social y político del socialismo(Wolkmer, 2017, pp. 24-28).

\footnotetext{
En suma, es claro que en la teoría crítica occidental de tradición ilustrada hay un lenguaje de carácter progresista que legitima una aspiración utópica y revolucionaria, conforme con lo más profundo de la dignidad humana. Sin caer en un pseudo-idealismo y/o cientificismo, el objetivo y significado positivo de la teoría crítica es, en tanto proyecto ideológico de desmitificación y emancipación, salvar y rescatar todo un contenido utópico-liberador del pensamiento occidental(Wolkmer, 2017, p. 31).
}

Para A.C. Wolkmer, en la década de los 1960 en Europa se pone en marcha una crítica a los límites delparadigma hegemónico dominante, positivismo jurídico, por su formalismo y normativismo. Sin embargo, el autor es consciente de que no es la primara resistencia en la historia. Ya a inicios del siglo XX, el realismo y el pragmatismo jurídico, tanto en Estados Unidos como en Escandinavia, habían reaccionado frente a ello. En el resurgimiento crítico a finales del siglo XX identifica varios factores: a) los aportes del derecho soviético, con sus críticas al derecho burgués (Stučkay Pasukanis); b) la influencia de Louis Althusser,en su relectura de la obra de A. Gramsci y Marx para explicar la estructura social; c) la críticas de la Escuela de Fráncfort, desde Alemania y Estados Unidos; d) el pensamiento de Michel Foucault con sus tesis arqueológicas y microfísica del poder (Wolkmer, 2017, p. 40).

\begin{tabular}{|l|l|l|l|l|}
\cline { 2 - 5 } Qevista Dialectus & Ano 5 & n.13 & Agosto - Dezembro 2018 & p. 27 - 77 \\
\hline
\end{tabular}




\section{FILOSOFÍA JURÍDICA LATINO AMERICANA EN EL SIGLO XXI...}

\section{Antonio Salamanca}

A. C. Wolkmer hace un rastreo para identificar espacios de pensamiento jurídico crítico en algunos países de la Europa occidental. En Francia, expresiones de crítica jurídica al paradigma dominante las reconoce en autores como A.J.Arnaud. En particular en la crítica semiológica-retórica, la crítica sociológica del "desvío” y del "discurso de la razón jurídica”. Se convierte en objeto de preocupación el acercamiento al derecho desde el pluralismo jurídico, la interdisciplinariedad, la globalización y la posmodernidad(Wolkmer, 2017, pp. 67-68). A finales de los años setenta se va a articular un fuerte movimiento de crítica jurídica al paradigma del derecho burgués formalista y normativista(Wolkmer, 2017, p. 67).En 1978, en el ámbito universitario se publica el manifiesto de un grupo de profesores universitarios la Association "Critique du Droit". Una de las pretensiones principales de ese movimiento es contribuir en la transformación epistemológica de la enseñanza y la investigación jurídica que se realiza en las universidades,para la "transición al socialismo". El paradigma epistemológico desde el que se hace la crítica y que se propone es el materialismo histórico-dialéctico. A. C. Wolkmer señala que este horizonte "desfetichizador" influyó en la filosofía político-jurídica (Michael Miaille, Maurice Bourjol, Jacques Michel, Philippe Dujardin); el derecho civil (G. de la Bradelle); el derecho del trabajo (A. Jeammaud, A. Roudill, G. Lyon-Caen); el derecho mercantil (Michel Jeantin); el derecho administrativo (J. J. Gleizal) (p.65). El movimiento, con los años, fue centrando su crítica en las relaciones del sujeto con las normas y las instituciones. Metodológicamente fue distanciándose del materialismo histórico-dialectico y caminando hacia una epistemología con cierta indefinición y eclecticismo(Wolkmer, 2017, pp. 63-65).

La crítica al sistema jurídico hegemónico se extendió a otros países europeos comoAlemania,Bélgica, España, Inglaterra, Italia y Portugal. En Italia, a finales de la década de los años sesenta del siglo XX, un grupo de jueces darán nacimiento al "uso alternativodel derecho". Este consiste en "la utilización del ordenamiento jurídico vigente y de sus instituciones en dirección de una práctica jurídica emancipadora, centrada en los sectores sociales o las clases menos favorecidas"(Wolkmer, 2017, p. 68). A. C. Wolkmer destaca como miembros de esta corriente a: Pietro Barcellona, Giuseppe Cortturri, Luigi Ferrajoli, Salvatore Senese, Venzo Accattatis, Alexandro Baratta, Eligio Resta. Dos son los postulados críticoscomunes en el movimiento: 1) el derecho (burgués) cumple una función política

\begin{tabular}{|c|c|c|c|c|}
\cline { 2 - 5 } & Ano 5 & n.13 & Agosto-Dezembro 2018 & p. $27-77$ \\
\hline
\end{tabular}


de dominación y producción capitalista; 2) el poder judicial es un aparato ideológico, de control y represión funcional al sistema para mantener el statu quo del capitalismo(Wolkmer, 2017, p. 70-72).

En España, la influencia del movimiento uso alternativo del derecho italiano tuvo eco en juristas como Nicolás López Calera, Modesto Saavedra López y Perfecto Andrés Ibáñez. También desde el iusnaturalismo (cristiano y neoescolástico), el positivismo jurídico (en sus variantes historicistas, sociologistas, funcionalistas, etc.) y planteamientos críticos con el derecho burgués se ha cuestionado, con mayor o menor alcance, al paradigma jurídico hegemónico. Con esta orientación crítica, A. C. Wolkmer identifica aautores como:Elías Díaz, Juan-Ramón Capella, Joaquín Herrera Flores, Francisco Javier de Lucas, María José Fariñas, David Sánchez Rubio, Antonio-Enrique Pérez Luño, Juan Antonio Senent de Frutos, entre otros(Wolkmer, 2017, pp. 76-79). En la obra de Joaquín Herrera Flores, Javier de Lucas y María José Fariñas, en particular, se pretende recuperar las categorías de "necesidades", "necesidades radicales", "necesidades históricas como categoría fundantes para una teoría de los derechos humanos(Wolkmer, 2017, pp. 80-81).

En Alemania, el autor entiende que más allá del acercamiento al derecho desde el formalismo sociológico sistémico, como es el caso de Niklas Luhmann, el momento crítico del derecho resurgió en autores como Ulrich Mückenberger y Dieter Hart, gracias a la influencia del uso alternativo del derecho. Asimismo, el pensamiento crítico de la hermenéutica (H.G.Gadamer), de la acción comunicativa (J. Habermas), la ética transcendental del discurso (K. O. Apel) y la justicia política (OtfriedHöffe) han mostrado sus influencias en reivindicaciones del derecho como "reflexión trascendental (Dietrich Böhler), como crítica del derecho (Wolf Paul)(Wolkmer, 2017, pp. 70; 73-75).

En Bélgica, la crítica se centró en asuntos como: a) sustituir la ciencia dogmática del derecho, como "la" ciencia del derecho, por la ciencia crítica del derecho; b) la necesidad de abordar el derecho desde su historicidad; c) la pluralidad histórica cultural e interdisciplinaria de expresarse el derecho en el espacio y el tiempo. A.C. Wolkmer ubica en esta órbitaa juristas como François Ost, Jacques Lenoble, Michael van de Kerchove, François Rigaux(Wolkmer, 2017, pp. 83-84).

\begin{tabular}{|l|l|l|l|l|}
\cline { 2 - 5 } Q Qovista Dialectus & Ano 5 & n.13 & Agosto - Dezembro 2018 & p. 27 - 77 \\
\hline
\end{tabular}




\section{FILOSOFÍA JURÍDICA LATINO AMERICANA EN EL SIGLO XXI...}

\section{Antonio Salamanca}

En Portugal, el autor destaca particularmente la obra de Boaventura de Sousa Santos, entre otras Sociología jurídica crítica (2009), Las bifurcaciones del orden (2018). Es especialmente significativa por sus aportes críticos al derecho denunciando: a) la hegemonía de un derecho burgués moderno, retórico, burocrático (profesionalizado) y violento; b) el colonialismo jurídico del derecho burgués); d) la reivindicacióndel pluralismo de otros derechos históricos y actuales desde una ecología de los saberes contrahegemónica y decolonial; e) con una hermenéutica diatópica para entender los derechos humanos(Wolkmer, 2017, p. 90-91).

En la década de los años 1980, el movimiento de crítica jurídica comienza a extenderse en América Latina enriqueciéndolo con aportes propios. El denominador común es el distanciamiento del positivismo jurídico, del iusnaturalismo y del realismo sociológico. La crítica se hacía desde diversos horizontes epistemológicos. Algunos de los autores con ese compromiso identificados por A. C. Wolkmer son:en Argentina,Carlos Cárcova, Ricardo Entelman, Alicia Ruiz, Enrique Marí; México, Oscar Correas; Chile, representantes como Eduardo Novoa Monreal; Colombia, el grupo de juristas que integrarán el Instituto Latinoamericano de Servicios Legales Alternativos (Ilsa); en Brasil, profesores de filosofía y sociología jurídica como Roberto Lyra Filho, Roberto A. R. Aguiar, Luiz Fernando Coelho y Luis Alberto Warat(Wolkmer, 2017, pp. 39-40).

A. C. Wolkmer diferencia dos posiciones predominantesen la crítica jurídica latinoamericana en la primera mitad de la década de los años 1980: a) la superación del derecho hegemónico burgués con una teoría crítica del derecho alternativa. En ese grupo ubica la obra de Michael Mialle y Ricardo Entelman; b) la superación del derecho hegemónico desde diversas epistemologías y movimientos fragmentados (L. A.Warat, L.S. Rocha). En la primera familia, la propuesta de M. Miallese hace en la tradición de la teoría marxista renovada del derecho, asumiendo el materialismo histórico. El derecho es más que un mero reflejo de la infra-estructura o ideología(Wolkmer, 2017, pp. 45-46). También en esta tradición se encuentran los aportes de Entelman. Su horizonte epistemológico se encuentra enriquecido fundamentalmente por el materialismo jurídico, la ideología althusseriana, la lógica lingüística, el pensamiento de Foucault y el psicoanálisis. El derecho se convierte en "una práctica social específica, en la cual se expresan los conflictos de los grupos sociales ac-

\begin{tabular}{|l|l|l|l|l|}
\cline { 2 - 5 } Q Qovista Dialectus & Ano 5 & n.13 & Agosto - Dezembro 2018 & p. 27 - 77 \\
\hline
\end{tabular}




\section{FILOSOFÍA JURÍDICA LATINO AMERICANA EN EL SIGLO XXI...}

\section{Antonio Salamanca}

tuantes en una formación social determinada, tanto en la producción, circulación y consumo del derecho, como en la producción teórica con relación a las instancia jurídica, y que adquiere cierta autonomía relativa en relación a la totalidad de la producción social"(Entelman, citado en Wolkmer, 2017, p. 46). En la segunda familia, L. A .Warat y L.S. Rocha comparten su advertencia de que la llamada "teoría crítica del derecho" termine cayendo en la falacia del dogmatismo de una nueva verdad positivista. Su propuesta es permanecer en la fragmentación de epistemologías jurídicas; en el relativismo y cierto nihilismo de las pretensiones de la teoría crítica del derecho. Desde la semiología del poder y la filosofía del lenguaje jurídico, Warat propone un conjunto de contralenguajes jurídicos sin pretensiones de constituir un cuerpo teórico sistemático(Wolkmer, 2017, pp. 48-53; 51).

En México, en el mapeo de A. C. Wolkmer, la crítica al derechose orienta en varias dimensiones: a) la denuncia al derecho burgués desde la tradición marxista. Esta tendencia se ubica en torno a la obra de Oscar Correa, en la Universidad de Puebla y en Instituto de Investigaciones Jurídica de la UNAM. La revista Crítica Jurídica ha articulado el espacio de muchas de estas luchas ideológica (v.gr. Alma Guadalupe Melgarito Rocha, Daniel Sandoval Cervantes); b) la reivindicación del derecho que nace del pueblo (democratización de las fuentes del derecho) desde un iusnaturalismo histórico analógico. Jesús Antonio de La Torre Rangel, en la Universidad de Aguascalientes es el autor de referencia; c) la reivindicación de la tradición propia emancipadora de los derechos humanos, en torno al trabajo de Alejandro Rosillo en la Universidad Autónoma San Luis Potosí, y la Revista de Derechos Humanos y Estudios Sociales (Redhes). Asimismo en interrelación con estas tres familias A. C. Wolkmerse hace eco de los trabajos de autores como Graciela Bensusan, Antonio Azuela, Daniel Sandoval, Napoleón Conde,los integrantes vinculados en algún momento con el colectivo RADAR, Mylai Burgos Matamoros, Yacotzin Bravo, Liliana López, Jorge Peláez y Aleida Hernández; y los profesores articulados en torno al Instituto Nacional de Ciencias Penales (Inacipe), como Fernando Tenorio Tagle, Alicia González Vidaurri, Augusto Sánchez Sandoval y Luis González Plascencia (Wolkmer, 2017, p. 94-98).

En Centroamérica y el Caribe A. C. Wolkmerencuentra influencias delpensamiento jurídico crítico en los siguientes campos: a) la educación jurídica; b) la epistemología y la historia del derecho; c) la teoría crítica de los derechos humanos; y d) el marxismo

\begin{tabular}{|c|c|c|c|c|}
\cline { 2 - 5 } & Ano 5 & n.13 & Agosto-Dezembro 2018 & p. $27-77$ \\
\hline
\end{tabular}


jurídico. En Costa Rica destacan la obra de Norman J. Solórzano, Helio Gallardo y Wlarter Antillón. En Cuba, la obra de Julio FernandezBulté, Julio Fernández Estrada, Delio J. Carreras Cuevas y Hugo M. Azcuy. En Puerto Rico, hacen una rica contribución el grupo de investigadores vinculados a la entonces Facultad de Derecho Eugenio María de Hostos, Carlos Rivera Lugo, Daniel Nina(Wolkmer, 2017, pp. 99-100).

En América del Sur, a juicio del A. C. Wolkmer,(2017, pp. 101-121)la crítica jurídica se ha centrado entre otras en los siguientes campos: a) la crítica al derecho en su tradición positivista, desde sus propias limitaciones. Con esa preocupación ubica a autores como Patricia Scarponetti, Ricardo Rabinovich-Berkman, Christian Courtis, Mauro Benente, Beatriz Rajhlan (Argentina); Luis Alberto Warat, Agostinho Ramalho Marques Neto, Luiz Fernando Coelho, Celso Ludwig, Alyssson Leandro Mascaro (Brasil); b) la crítica de la ideología burguesa del derecho como elemento de dominación y resistencia al cambio. Ejemplo de ello para Wolkmerson las obras:Carácter ideológico de la filosofía del Derecho (1988), de Gilberto Tobón Sanín (Colombia); Luchas obreras y política laboral en Colombia(1978), (con Víctor Manuel Moncayo), y Derechos Humanos y crítica social en América Latina (1984), Criminalidad y Constituyente (1977), de Fernando Rojas (Colombia); El Derecho como obstáculo al cambio social (1980), del autor Eduardo Novoa Monreal (Chile); c) la praxis emancipadora alternativa del derecho orientada a la vida ("satisfacción de las necesidades fundamentales"). Ejemplo de ello es la obra Una concepción metodológica del uso alternativo del Derecho (1988), de Manuel Jacques (Chile) y la actividad del Instituto Latinoamericano de Servicios Legales Alternativos (Ilsa), con su revista El otro Derecho(Wolkmer, 2017, pp. 101-106); d) el derecho que surge de abajo, el derecho hallado en la calle. Es el caso del trabajo por la justicia comunal y la legalidad campesina de Antonio Alfonso Peña Jumpa, Raquel Z. Yrigoyen Fajardo y Pavel H. Valer-Bellota (Perú); Roberto Lyra Filho, Jose Geraldo de Souza Jr. (Brasil); e) el pluralismo jurídico crítico, de A. C. Wolkmer (Brasil); f) el constitucionalismo andino, entre ellos se encuentran los trabajos de Ramiro Ávila, Luis Ávila, Raúl LLásag, Juan Montaña, Gina Chávez (Ecuador);Farit L. Rojas Trudela, Ramiro Molina Rivero, Marcelo Fernández Osco, Diego Tejada,Carlos Derpic, Juan Ramos Mamani(Bolivia); y el constitucionalismo horizontal, de Alejandro Médici (Argentina); g) la criminología crítica. Esta orientación se encuentra en la obra de autores

\begin{tabular}{|l|l|l|l|l|}
\cline { 2 - 5 } Q Qovista Dialectus & Ano 5 & n.13 & Agosto - Dezembro 2018 & p. 27 - 77 \\
\hline
\end{tabular}


como Rosa del Olmo, Elsie Rosales, Lola Aniyar de Castro, Manuel Eugenio Gándara (Venezuela); h) el acceso a la justicia de los más pobres, por ejemplo, en la obra,de 2009, Una interpretación histórica-institucional del Acceso a la Justicia en Venezuela (1936-2006), de Sonia BoueiriBassil (Venezuela); i) el eclecticismo metodológico y la interdisciplinariedad. Es el caso de la obra de Ricardo Entelman, en acercamientos a la epistemología foucaultiana y el psicoanálisis,Carlos M. Cárcova y Enrique Zuleta Puceiro (Argentina); j) la función psicológica opresora del texto de la ley. En este sentido encontramos la obra de Enrique E. Marí (Argentina); k) la producción del conocimiento jurídico. El grupo ALMED es un ejemplo de ello desde 1974. Se crea por juristas argentinos y brasileños en la Universidad de Morón, fundamentalmente a través de la revista Contradogmática. Su pretensión es desmitificar la cultura jurídica del derecho hegemónico con el objetivo de crear conciencia crítica entre los juristas. Siguiendo a Warat los objetivos principales de esta crítica son:

\begin{abstract}
a) la vía de cuestionamiento de las escuelas de Derecho; b) la tendencia de reformulación crítica de las bases epistemológicas de la producción del conocimiento científico, tomando la teoría jurídica como forma social a ser explicada y no como explicación de lo real; c) la vía semiológica obtenida a partir del desplazamiento y de la deconstrucción del paradigma semiológico dominante, que, basado en presupuestos positivistas y empiristas, se presentaba como extremadamente insuficiente para mostrar el poder de las significaciones como elemento de organización, legitimidad y reproducción de las relaciones sociales(Warat, 1984, p. 22).
\end{abstract}

Estas corrientes de pensamiento crítico no son las únicas en América Latina. También existen las que se insertan en las tradiciones nihilistas y deconstructivistas. Sin embargo, a juicio de A.C. Wolkmer, en su postulados críticos no han tenido presente los lugares epistémicos propios periféricos (coloniales) que hacen ver la realidad y su liberación (revolución) con mayor complejidad y particularidad: "En verdad, las teorías críticas (como los modismos nihilistas y deconstructivistas) construidas por las élites pensantes del Norte no han tenido en cuenta los problemas del colonialismo, del feminismo, de la raza, las minorías multiétnicas ni de los refugiados"(Wolkmer, 2017, p. 34).

Es por esta razón, entre otras, que autores como Boaventura de Sousa Santos reclaman y apuestan por una teoría crítica "situada" donde está, en la periferia colonial; y no enajenadamente elaborada desde los centros metropolitanos —en el mejor ejemplo de colonialismo interno_-, aunque se viva en el llamado Tercer Mundo: "Por el contrario, para

\begin{tabular}{|l|l|l|l|l|}
\cline { 2 - 5 } Q Qovista Dialectus & Ano 5 & n.13 & Agosto - Dezembro 2018 & p. 27 - 77 \\
\hline
\end{tabular}


la teoría crítica post-moderna, todo el conocimiento crítico tiene que comenzar por la crítica del propio conocimiento. En la fase actual de transición paradigmática, la teoría crítica post-moderna se construye a partir de una tradición epistemológica marginada y desacreditada de la modernidad: el conocimiento-emancipación” (Santos, 2003, p. 31). A ello añade A. C. Wolkmer "y movida por el principio de solidaridad" (Wolkmer, 2017, p. 35).

Para Wolkmer, la teoría crítica en el ámbito jurídico debe construirse desde una crítica decolonial, pluralista, intercultural e interdisciplinar. Él propone un enriquecimiento del derecho con los aportes de: a) teología y filosofía de la liberación (Gustavo Gutiérrez, Ignacio Ellacuría, Leonardo Boff, Enrique Dussel); b) la educación conscientizadora popular (Paulo Freire); c) la investigación de la praxis sociológica (Orando Fals Borda); d) la antropología del hombre latinoamericano (Darcy Ribeiro, Rodolfo Kusch); e) la economía de la dependencia (Theotônio Santos, A. Gunder Frank, Ruy Mauro Marini); f) la descolonización de los espacios geográficos (Milton Santos); g) el indigenismo; h) el feminismo; i) el "nuevo" constitucionalismo latinoamericano (Wolkmer, 2017, p. 36).

Una vez concluido este mapeo del pensamiento jurídico crítico en nuestra Amé-

rica, A. C. Wolkmer se hace eco — que compartimos- de las limitaciones de la crítica emancipatoria sin proyecto revolucionario. Cita para ello a Ph. Slater, en Origen y significado de la Escuela de Frankfurt (1978),donde advierte: “.....[m]ostrar tan sólo la necesidad de las contradicciones y tener consciencia de ellas no es suficiente; una real teoría revolucionaria incluye una teoría de la organizacióny acción política. Es precisamente una teoría crítico-práctica. Y es exactamente de eso que carece la concepción de la Escuela de Frankfurt” (Ph.Slater en Wolkmer, 2017, p. 34). Es por ello que para A. C. Wolkmer, el desafío de una filosofía y teoría jurídica crítica es "recuperar y reconstruir la noción de utopía en la perspectiva de la comunidad, de lo común, potencializando nuevos modos de resistencia”(Wolkmer, 2017, p. 37). "En síntesis, pensar y operar una teoría crítica alternativa/descolonial implica ir más allá de los marcos emancipatorios de la tradición moderna, esencialista, racionalista y eurocéntrica; es dirigirse a una construcción realista, contextualizada y transformadora de los espacios societarios, políticos y culturales subalternos”(Wolkmer, 2017, p. 37). Para Wolkmer la teoría jurídica crítica es: “la formulación teórico-práctica capaz de cuestionar y de romper con lo normativo que está disciplinaria-

\begin{tabular}{|l|l|l|l|l|}
\cline { 2 - 5 } Q Rovista Dialectus & Ano 5 & n.13 & Agosto - Dezembro 2018 & p. 27 - 77 \\
\hline
\end{tabular}




\section{Antonio Salamanca}

mente ordenado y oficialmente consagrado (en el conocimiento, en el discurso y en procedimiento práctico) en dada formación social, y como la posibilidad de concebir y operar otras formas diferenciadas, no represivas y emancipadoras, de práctica jurídica”(Wolkmer, 2017, p. 41).

Este sentir parece ser compartido por autores que vienen de otras tradiciones, como M. Atienza. En 2014 publicó el artículo “Una Filosofía del Derecho para el mundo Latino. Otra vuelta de tuerca'. En el documento, M. Atienza presenta un Manifiesto, en forma de decálogo, sobre lo que podrían ser postulados de un nuevo paradigma jurídico (Atienza, 2017, pp. 48-51). En el segundo postulado reclama la necesidad de desarrollar teorías jurídicas regionales en el horizonte de un multilateralismo jurídico frente a la globalización de los localismos.

La elaboración de una teoría del Derecho completamente general, válida para cualquier sistema jurídico, es una empresa de valor limitado. Pero, además, no es nada obvio que la teoría jurídica al uso, el paradigma angloamericano dominante (positivista o no), sea verdaderamente general. Por eso, ante el riesgo cierto de que la globalización en la teoría del Derecho responda más bien a lo que se ha llamado la "globalización de un localismo", podría ser de interés desarrollar teorías del derecho -digamos- "regionales", de acuerdo con los diversos círculos de cultura hoy existentes. El multilateralismo parece una estrategia deseable, y no solo en el ámbito de la política internacional(Atienza, 2017, p. 49).

Para M. Atienza, un modelo de teoría del derecho (crítica, transformadora) podría hacerse combinando el positivismo jurídico, el iusnaturalismo y la teoría crítica del derecho. "Un modelo de teoría del Derecho pragmáticamente útil y culturalmente viable en nuestros países bien podría consistir en combinar estos tres ingredientes: método analítico, objetivismo moral y transformación social. Cada uno de ellos está especialmente vinculado a una de las grandes concepciones del derecho bajo las cuales se suele clasificar, entre nosotros, a los filósofos del Derecho: el positivismo jurídico, el iusnaturalismo y la teoría crítica del Derecho.’(Atienza, 2017, p. 50). En 2017 publica su obra Filosofía del Derecho y transformación social.En ella defiende que el derecho debe servir para la transformación social. Y encuentra esta dimensión en las teorías críticas del derecho.

Los aspectos más valiosos de las teorías críticas del Derecho giran en torno a la necesidad de insertar el derecho (y la teoría del Derecho) en el medio social y

\begin{tabular}{|l|l|l|l|l|}
\hline Qovista Dialectus & Ano 5 & n.13 & Agosto - Dezembro 2018 & p. 27-77 \\
\hline
\end{tabular}




\begin{abstract}
plantearse su potencial de transformación social. Esa concepción (o una cierta manera de entenderla) muestra así la necesidad de que la teoría del Derecho incorpore ciertas categorías que generalmente quedan fuera del análisis (conflicto, trabajo, poder, necesidad social), asuma el carácter histórico del Derecho y de las categorías jurídica, y preste atención a los elementos desigualitarios e ideológicos del Derecho (también de los Derechos del Estado constitucional)(Atienza, 2017, pp. 50-51).
\end{abstract}

Pues bien, llegados a este punto de coincidencia en el reclamo, lo que entendemos se está necesitando es un paradigma jurídico (nuevo). Nos encontramos en los estertores del geocentrismo jurídico. No creo que el iusnaturalismo, ni el iuspositivismo, ni un cóctel con la teoría crítica del derecho puedan dar cuenta, explicación coherente, de la vida jurídica de los pueblos y la naturaleza. Eso que M. Atienza llama:postpositivismo, y A. C. Wolkmer: pluralismo jurídico crítico o teoría crítica del derecho son los gritos de alumbramiento de una nueva criatura que siempre estuvo con nosotros.

\title{
3. La (re)insurgencia del iusmaterialismo en el siglo XXI
}

La insurgencia del iusmaterialismo en el siglo XXI se debe a dos grandes causas fundamentalmente: a) el grado creciente global deopresión de las grandes mayorías; de los pueblos y la naturaleza, a través de un sistema normativo que se presente como pretendidamente "jurídico". Existe una progresiva desafección por pérdida de legitimación del positivismo jurídico como paradigma dominante, aunque no de poder violento (ni de su reforzamiento ideológico con el sacerdocio de operadores jurídicos). Respecto a la dominación, más bien de lo que somos testigos es de su creciente despotismo; b) el agotamiento explicativo, primero del iusnaturalismo y ahora del iuspositivismo como teorías jurídicas. El dominio de sus postulados teóricos está agotado. Ha quedado evidenciado como un horizonte: (i) ecléctico, (ii) sin una teoría integrada de la acción; (iii) perdido en la especialización y fragmentación de múltiples teorías; (iv) incapaz de explicar, como el iusnaturalismo, de modo coherente las nuevas investigaciones y desafíos provenientes del mundo vivo de los derechos, del derecho (Salamanca, 2015, p. 86). También en América Latina, el iusnaturalismo y positivismo jurídico, como paradigmas del derecho hegemónicos desde la Conquista, el primero hasta el siglo XIX y el segundo desde entonces hasta hoy, han mostrado sus limitaciones e insuficiencias explicativas sobre lo que sea la realidad de los derechos de

\begin{tabular}{|l|l|l|l|l|}
\cline { 2 - 5 } Qevista Dialectus & Ano 5 & n.13 & Agosto - Dezembro 2018 & p. 27 - 77 \\
\hline
\end{tabular}


los pueblos y la naturaleza, así como de la disciplina del derecho. Su funcionalidad con el poder de dominación ha tenido como contraparte obligada, en palabras de M. Atienza, “....la falta de atención a los problemas y a los destinatarios”. Esta es una de las principalesexplicaciones "de la insatisfactoria situación de la Filosofía del Derecho en los países latinos" (Atienza, 2017, p. 50).

Como hemos apuntado, yendo muy al fundamento, gran parte de las limitaciones explicativas del iusnaturalismo le vienen porque asume "dogmáticamente" que existen derechos naturales, que los seres humanos nacen con derechos innatos. Confunde el sistema de necesidades/capacidades, constante de la especie homo sapiens sapiens, con una creación histórica de la comunidad que es el sistema de derecho (naturales-humanos). Por su parte, el iuspositivismo asume también "dogmáticamente" que el derecho, los derechos de los pueblos (y los derechos humanos) tienen su legitimación última en la voluntad, sea individual o intersubjetiva. Es el único asidero que les queda después de haber dinamitado, también dogmáticamente, la dimensión debitoria, moral (ética) de la praxis así como la posibilidad de conocerla. El pedigrí epistemológico último del positivismo es su escepticismo cognitivo y moral: a) la realidad no se puede conocer sino que solo podemos hablar del mundo fenoménicamente construido por la intersubjetividad;y b) del ser no se puede obtener el deber ser. Estos dogmas les impiden a ambos paradigmas dar una explicación más completa, y susceptible de probación sin contradicciones, del hecho jurídico, del hecho del Derecho. Ahora bien, esto no quiere decir que ambos paradigmas hayan dejado de ser utilizados por el poder violento socialo vayan a dejar de hacerlo. Eso solo ocurrirá si encuentran otro que le sirva mejor para pretender la legitimación de la violencia institucional. Hoy, como aún no hay otro, lo que se evidencia es una propagación global del positivismo jurídico en todas sus variantes (v.gr. China, Rusia, etc.) (Salamanca, 2017).

Sin embargo, desde la noche de los tiempos, me atrevería a decir que desde que hay sociedad, comunidad humana, desde la aparición de la especie del homo sapiens sapiens hace 200.000 o algo más (y tal vez también en la familia de los homo sapiens neandertales), ha estado alumbrándose por doquier nuevas constelaciones jurídicas(Ribas Alba, 2015, pp. 44-52). Se han diseminado a lo largo y ancho del planeta. La mayoría de ellas iletradas y"analfabetas"- solo una pocas pasaron por las escuelas y universidades-. Sus to-

\begin{tabular}{|l|l|l|l|l|}
\cline { 2 - 5 } Q Qovista Dialectus & Ano 5 & n.13 & Agosto - Dezembro 2018 & p. 27 - 77 \\
\hline
\end{tabular}




\section{FILOSOFÍA JURÍDICA LATINO AMERICANA EN EL SIGLO XXI...}

\section{Antonio Salamanca}

gas fueron sus harapos hechos girones por las luchas; sus cortes y palacios de justicia: los campos y patios traseros de los pueblos y suburbios. Sus discursos, argumentaciones, resoluciones y sentencias: frases incompletas de silogismos motivados sin falacias. Este ha sido el mundo jurídico de los pobres y oprimido; el derecho consuetudinario de los pobres en la historia de la humanidad. Este derecho, siempre insurgente, hoy está de regreso, vuelve; ¡vuelve la insurgencia del derecho de los oprimidos, de los pobres de la tierra! Su paradigma innominado por miles de años queremos reconocer; puede ser nombrado: puede llamarse iusmaterialismo.

El iusmaterialismo no nació históricamente con la pretensión fundamentalmente de hacer interlocución con teóricos del derecho. Fue un paradigma jurídico nacido de, con y para los pueblos y la naturaleza; fue y es el derecho de las grandes mayorías desposeídas. Con palabras de M. Atienza, "[1]a filosofía del derecho no es un género retórico, pero una forma equivocada de practicar la teoría jurídica consiste en desentenderse de quiénes son los destinatarios de los escritos iusfilosóficos y de quiénes pueden hacer uso de las ideas que se encuentran en ellos. Quizás no tenga sentido producir obras destinadas únicamente a otros filósofos del Derecho, y menos aún cuando sus destinatarios directos parecerían ser intelectuales a los que todo lo que se genera fuera de su ámbito cultural les es ajeno"(Atienza, 2017, p. 49).

Los padrinos de bautismo son una joven pareja y un amigo de toda la vida de lucha: K. Marx, Jenny vonWestphalen y F. Engels(Gabriel, 2013). En el siglo XIX, en Alemania, el joven K. Marx de 24 años, el irreductible profeta de los debates en la Gaceta Renana,cuando querían criminalizar como robo el uso de la leña de los bosques por los pobres para calentar el hogar en los fríos inviernos, reconoce y levanta su voz profética por el derecho de los pobres(Marx, 2007). Reconoce un derecho que viene de lejos en la historia, y del mismo se hace portavoz: el derecho consuetudinario de los pobres. Toda su vida la dedicó alverdadero empoderamiento jurídico de los pobres, oprimidos y explotados, denunciando al tiempo el engaño, el fetichismo, de un pseudoderecho: el derecho burgués. Contraderecho que no es sino el interés del capital sacralizado en ley. Sin embargo, su compromiso extenuante al empoderamiento de los oprimidos con una filosofía-teoría económica revolucionaria no le dejó tiempo para explorar la teorización del derecho insurgente de

\begin{tabular}{|l|l|l|l|l|}
\cline { 2 - 5 } Q Qovista Dialectus & Ano 5 & n.13 & Agosto - Dezembro 2018 & p. 27 - 77 \\
\hline
\end{tabular}


los pobres. Pero la crítica al derecho burgués de K. Marx, y buena parte del marxismo, es eso, una crítica derivada de la filosofía-teoría económica marxista al capital y al derecho del capital. La crítica a una teoría no es necesariamente la propuesta de otra teoría. K. Marx no elaboró una teoría marxista, comunista, del derecho histórico de los pobres. Esta es la tesis común y compartida por muchos autores, entre ellos Roberto Lyra Filho. En sus obras Karl, meu Amigo: Diálogo com Marx sobre o Direito (1983a)y Humanismo dialéctico (1983b) reconoce que la tradición marxista tampoco ha ofrecido una teoría marxista (comunista) del derecho por seis dificultades fundamentales: $1^{\circ}$ ) el mal uso e interpretación de las fuentes en la obra de K. Marx; $2^{\circ}$ ) la falta de sistematicidad en la presentación de la epistemología (del método) marxista y de la "ontología" del derecho; $3^{\circ}$ ) el desliz en el sofisma de incluir en el concepto de derecho cosas diversas y aisladas del fenómeno jurídico (en especial colocar al derecho en la esfera de la supraestructura, de la ideología); $4^{\circ}$ ) acercarse al derecho desde una historia dicotómica: "viejo/nuevo", "falso/verdadero", "improductivo/fecundo"; $5^{\circ}$ ) el prejuicio ideológico de identificar el derecho, la justicia y la educación jurídica con lo más reaccionario e ilegítimo de la sociedad; $6^{\circ}$ ) el dogmatismo metodológico de los investigadores marxista que recaen en el objetivismo, en el irracionalismo o en también en el subjetivismo(Wolkmer, 2017, pp. 128-131).

\begin{abstract}
se vuelve patente que Marx no repensó el Derecho globalmente, ni poseyó una única teoría o doctrina jurídica, habilitada a pensarlo de forma que fundamente (dialécticamente) el Derecho de resistencia y rebelión contra explotadores y opresores y valorar las normas de clases y grupos en conflicto. Se le escapa, inclusive, el Derecho de rebelión, este aspecto de la doctrina político-jurídica liberal, que tanto estorba a los positivistas-legalistas"(Lyra en Wolkmer 2017, pp. 131-132).
\end{abstract}

Ahora bien, coincidiendo con A. C. Wolkmer y E. Díaz, el marxismo no es un páramo o una fuente seca para el derecho. En palabras de E. Díaz, cabe:“‘... encontrar en la obra de Marx elementos suficientes - aunque, como ya se afirmó, no exento de ambigüedades - para construir dicha teoría, y, a partir de esta, como resultado no dogmático, una posterior teoría marxista del Derecho y del Estado"(Díaz, 1984, pp. 166; 170-172; Wolkmer, 2017, p. 132). Con toda humildad y asumiendo todos las limitaciones de quien se adentra en un mundo desconocido, es lo que hemos intentado en Teoría Socialista del Derecho (2011). La opción no es quedarse en una crítica posmoderna, relativista y nihilista del derecho burgués, lingüística, discursivamente sofisticada sino caminar hacia una derecho

\begin{tabular}{|l|l|l|l|l|}
\cline { 2 - 5 } Qevista Dialectus & Ano 5 & n.13 & Agosto - Dezembro 2018 & p. 27 - 77 \\
\hline
\end{tabular}


entendido como "praxis social que realice las necesidades de vida de los excluidos...de aplicabilidad de un Derecho verdaderamente justo"(Wolkmer, 2017, p. 55).A. C. Wolkmer recoge algunas de las exigencias del nuevo paradigma jurídico, expuestas por L. A. Warat,que pueda elaborarse en la tradición marxista. El nuevo paradigma jurídico crítico debe:

1)mostrar los mecanismos discursivos a partir de los cuales la cultura jurídica se convierte en un conjunto fetichizado de discursos; 2) denunciar cómo las funciones políticas e ideológicas de las concepciones normativistas del Derechos y del Estado se encuentran apoyadas en la ilusoria separación del Derecho y de la Política y en la utópica idea de la primacía de la ley como garantía de los individuos; 3) revisar las bases epistemológicas que guían la producción tradicional de la ciencia del Derecho, demostrando cómo las creencias teóricas de los juristas en torno de la problemática de la verdad y de la objetivad cumplen una función de legitimación epistémica, mediante la cual se pretende desvirtuar los conflictos sociales, presentándolos como relaciones individuales armonizables por el Derecho; 4) superar los bizantinos debates que nos muestran el Derecho desde una perspectiva abstracta, forzándonos a verlo como un saber eminentemente técnico, destinado a la conciliación de intereses individuales, a la preservación y a la administración de intereses generales [...]De esta forma, la teoría crítica intenta reubicar el Derecho en el conjunto de las prácticas sociales que lo determinan [...]; 5) crear una consciencia participativa que permita a los diferentes juristas involucrarse con efectividad en los múltiples procesos de decisión como factores de intermediación de las demandas de la sociedad y no como agentes del Estado [...]; 6) modificar las prácticas tradicionales de la investigación jurídica a partir de una crítica epistemológica de las teorías dominantes, de sus contradicciones internas y de sus efectos ideológicos con relación a los fenómenos que pretende organizar y explicar; 7) proporcionar, en las escuelas de Derecho, un instrumental pedagógico adecuado para que los estudiantes puedan adquirir un modo diferente de actuar, pensar y sentir a partir de una problemática discursiva que busque mostrar no sólo la vinculación del Derecho con las relaciones de poder, sino también el papel de las escuelas de Derecho como productoras de ideas y representaciones que luego se entrelazaron en la actividad social como un valor a priori, pleno de certezas y dogmatismo"(Warat en Wolkmer, 2017, pp. 42-43).

El iusmaterialismo, con la humildad y marginación de los pobres, irrumpe llamando otra vez en la historia a la puerta del saber jurídico. Es la apertura del viejo paradigma silenciado, abre un campo de saber jurídico, otea una pléyade de posibles teorías jurídicas en su constelación. Una de esas teorías, con sus limitaciones y aciertos, es la propuesta Teoría Socialista del Derecho (2011). Como hemos expresado arriba, una entre otras muchas posibles.El iusmaterialismo es un viejo modo de vivir (de sentir, de pensar y de realizar) el mundo jurídico de los pueblos y la naturaleza. Desde este momento histórico apenas se puede conocer en profundidad a este anciano amigo. Apenas si le estamos reconociendo.

\begin{tabular}{|c|c|c|c|c|}
\cline { 2 - 5 } & Ano 5 & n.13 & Agosto - Dezembro 2018 & p. $27-77$ \\
\hline
\end{tabular}




\section{FILOSOFÍA JURÍDICA LATINO AMERICANA EN EL SIGLO XXI...}

Antonio Salamanca

En un germinal diálogo de descubrimiento le hacemos tres preguntas con la intención de encontrar algunos rasgos (algunos postulados) que revelen su desconocido modo de existencia.Son apenas tres cuestiones para abrir el diálogo: 1) ¿qué nos dice, amigo, de lo que es el derecho, los derechos de los pueblos y la naturaleza; porque estamos hastiados y no satisfacelo que han predicado los sacerdotes del iusnaturalismo e iuspositivismo?: 2) ¿y por qué el derecho es eso que dice el iusmaterialismo?; 3) ¿y por qué el iusmaterialismo puede decir eso del derecho? Lo que sigue ha sido desarrollado en Filosofía de la Revolución (2008), Política de la Revolución (2008),Teoría Socialista del Derecho (2011) e Investigación Jurídica Interdisciplinar e Intercultural (2015: 86-89).

\section{I. ¿Qué es el derecho y los derechos de los pueblos y la naturaleza para el iusmateria- lismo?}

La buena noticia jurídica que nos susurra este sabio anciano milenario, pobre e iletrado, es que los derechos de los pueblos y la naturaleza (el derecho) es un sistema integrado de acciones (praxis) con poder real de satisfacer sus respectivos sistemas integrados de necesidades/capacidades, positivadas como bienes jurídicos para la producción, reproducción y florecimiento de sus vidas, de modo autónomo por la comunidad, con la ayuda tutelar de la fuerza coactiva comunitaria.A esta respuesta, que se nos deja como el canto de los pájaros de Anthony de Mello en la India, le preguntamos de nuevo:

\section{II. ¿Y por qué el derecho, los derechos, son eso que dice el iusmaterialismo?}

La respuesta:"Siete son los senderos del caminoiusmaterialista":

$1^{\circ}$. La vida y la reproducción de la vida de los pueblos con la Naturaleza es la última instancia de fundamentación y legitimación jurídica. El derecho tiene una finalidad: su telos (fin) es la vida. El derecho no es una estructura sin finalidad, no es un armazón funcional, un aparejo para cualquier cosa, una autopoiesis desnortada. Esta finalidad es "cosustantiva" a la praxis jurídica. El derecho sin su finalidad no es tal derecho, será otra cosa, pero no derecho. Sin embargo, la finalidad última del derecho no es cualquiera. No es el poder, ni la coordinación de acciones sociales, ni la legitimación del monopolio de la "violencia legítima" de la sociedad, ni la reproducción del sistema social, ni la legitimación o el instrumento de dominación de una clase social sobre otra, etc. La finalidad del derecho

\begin{tabular}{|c|c|c|c|c|}
\cline { 2 - 5 } & Ano 5 & n.13 & Agosto-Dezembro 2018 & p. $27-77$ \\
\hline
\end{tabular}


es la producción, reproducción y florecimiento de la vida de los pueblos y la naturaleza. Esta finalidad no es una autorreplicación cerrada, sino abierta; un dinamismo "necesario", constante, para la producción de la vida, pero abierto permanentemente al "azar" de la innovación, del florecimiento de las capacidades. El iusmaterialismo es un paradigma biojurídicoen el seno de la acción cómica. El iusmaterialismo se integra en las teorías biocéntricas de la Tierra (Gaia) (Lovelock, 2007); en la tradiciones biocéntricas de los pueblos originarios que sienten viva la Tierra como Madre, como Pachamama (v.gr. pueblos andinos Bolivia, Ecuador, Perú, etc.), en las tradiciones de los pueblos budistas, de los pueblos animistas africanos, etc.

$2^{\circ}$.La praxis (acción) como la mediación última ineludible de toda actividad cognitiva, afectiva y transformadora. La praxis, la acción, es la expresión última, la mediación ineludible e inescapable, históricamente encarnada, radical, en que acontece la vida de los pueblos y la naturaleza. El derecho es por tanto "praxis de vida". La mediación última no son los actos, ni las actuaciones, ni las actividades con sentido. Actos y actividades son partes o modos de las acciones (de la praxis). Ahora bien, la praxis no es 'solo' la 'práctica', las 'actuaciones'; el momento de ejecutivo de las acciones. No es el activismo.

La praxis tiene una estructura permanente. Esta consta de tres dimensiones. Una primera es la volición ejecutiva. Tal vez la más cercana por cómo se nos aparece en el discurrir de cada día, es en uno de sus momentos como(i) "la volición en ejecución", que habitualmente entendemos reductivamente como "práctica", como la "actuación.Sin embargo, la ejecución es el último momento (de tres) de la "volición en ejecución". La ejecución de las acciones es posibilitada por una dimensión previa de (ii)“autodeterminación” de la voluntad (segundo momento). Estase asienta, a su vez, en una dimensión material previa de la praxis que es la (iii) "liberación” del enclaustramiento del mundo de las cosas.

Ahora bien, la praxis, como parte de la acción cómica, tiene dos dimensiones además de la volición en ejecución. En segundo lugar, no por orden de importancia, sino expositivo, la praxis es comunicación sentiente con el mundo de la vida de los pueblos y la naturaleza;es afección tónica (emocional, afectiva, empática, sensitiva) con la realidad. Esta segunda dimensión de la praxis tiene también su estructura interna articulada en tres mo-

\begin{tabular}{|l|l|l|l|l|}
\cline { 2 - 5 } Q Qovista Dialectus & Ano 5 & n.13 & Agosto - Dezembro 2018 & p. 27 - 77 \\
\hline
\end{tabular}




\section{FILOSOFÍA JURÍDICA LATINO AMERICANA EN EL SIGLO XXI...}

Antonio Salamanca

mentos. Es (iv) comunicación eco-estética, que posibilita una (v) comunicacióneroeconómica, que a su vez, permite (vi) la comunicación político-institucional.

En tercer lugar, la praxis es ademásaprehensióncognitiva del mundo de la vida de los pueblos y la naturaleza. La actividad cognitiva de los seres humanos no es solo, ni principalmente, ni siempre (vii) aprehensión racional. Este tercer momento cognitivo reposa sobre (viii) una aprehensión sentiente cognitiva analítico-dialéctica (sistémica), que a su vez es posibilitada por (ix) la aprehensión sentiente "informativa" de los hechos del mundo de la vida de los pueblos y la naturaleza.

La praxis, como mediación radical estructurante e históricamente encarnada, de la vida de los pueblos y la naturaleza, es la fuente primaria inescapable del derecho. Por ello el derecho insurgente iusmaterialista reivindica la praxis de la costumbre como la fuente primera y principal de los derechos a largo de los tiempos. La ley es más que el fetiche de la mediación escrita; la ley, si viene a la vida es como praxis, como un modo de costumbre jurídica. Es una práctica mediada por el texto escrito. Esta subversión jurídica permite entender y fundamentar la diversidad de fuentes del derecho en el pluralismo jurídico. El derecho nace de los pueblos, desde abajo, en cada rincón que hay comunidad humana. Pero de los pueblos, no hay que olvidar, quetambién nace, por cierto, algo que unos pocos quieren enquistar como derecho: el contraderecho, muchas veces cooptando las instituciones populares de autogobierno para fabricar el fetiche jurídico.

Por ello el iusmaterialismo afirma que la realidad de las fuentes del derecho (frente a la enajenación jurídica) es la democratización popular de los sujetos productores de derechos. Los derechos no se producen en las facultades de derecho de las universidades, ni exclusivamente en las asambleas legislativas de los órganos centrales de los países. Allá se genera y se glosa el texto normativo. Este puede o no referirse al verdadero derecho vivo que trascurre todos los días en los intersticios del mundo de la vida de las relaciones sociales y medioambientales.Este modo de entender la praxis popular, plural e intercultural, permite responder, por ejemplo, a las exigencias "postpositivistas" del Manifiesto de M. Atienza:

Si el Derecho - como alguna vez se ha escrito- es "una gran acción colectiva que transcurre en el tiempo", una práctica social, entonces la teoría del Derecho tiene, de alguna manera, que formar parte de esa práctica. Una consecuencia de

\begin{tabular}{|c|c|c|c|c|}
\hline Q Rovista Dialectus & Ano 5 & n.13 & Agosto - Dezembro 2018 & p. $27-77$ \\
\hline
\end{tabular}


ello es que el teórico del Derecho no puede ser ajeno a los valores de esa práctica, ni puede tampoco concebir su participación en la misma en términos puramente individuales. Lo que debería guiar nuestro trabajo, en definitiva, no es el afán de originalidad, sino de participar cooperativamente con otros en la mejora de esa práctica"(Atienza, 2017, pp. 48-49).

$3^{\circ}$.La praxis de vida esel dinamismo histórico material del sistema de necesidades/capacidades de los pueblos y la naturaleza por su producción, reproducción y florecimiento. El derecho, los derechos de los pueblos y la naturaleza tienen un motor que anima la materialidad de la vida de la praxis. Sí, la praxis vital tiene un motor que no se mueve solo por ideas fantasmagóricas o espectrales. Como no somos ángeles, las ideas en los seres humanos forman parte de un motor histórico que mueve las sociedades, las personas y la vida en la naturaleza. Este motor es completamente material o energético, sin dualismo hilemórficos (materia vs forma; cuerpo vs alma; pasiones de la carne vs. virtudes del espíritu). La superación del dualismo de la metafísica occidental, bien asentado por la influencia aristotélica y acogido por la Iglesia Católica casi por dos mil años, es una de los grandes aportes del iusmaterialismo. Los aportes de las indagaciones de K. Marx y F. Engels, así como de X. Zubiri han sido claves. Pues bien, este motortal vez sea la palanca de Arquímedes. El motor de la vida en el planeta es el dinamismo histórico de satisfacción del sistema de necesidades/capacidades ( $s n c$ ) para la producción, reproducción y florecimiento de la vida. La vida no es un todo indiferenciado, no es una quimera, no es una interpretación subjetiva o intersubjetiva, no es una realidad angelical. Por el contrario, la vida es el florecimiento histórico de cómo los pueblos y la naturaleza buscan, satisfacen y florecen en un grado u otro el sistema de necesidades/capacidades compartido.

Las necesidades/capacidades del sistema no son infinitas. Son finitas. Forman parte de un sistema estructural compartido por todas las especies vivas. Un sistema que modula su expresión según cada especie, pero que es constante con la especie. Se expresa históricamente pero no cambia salvo que cambie la especie. Las necesidades/capacidades son objetivas no subjetivas; son finitas, no infinitas; son el origen de los deseos, no los deseos el origen de las necesidades/capacidades;son el origen y fuente de las verdaderas reivindicaciones y demandas. Para satisfacerse necesitan de satisfactores. Estos son creaciones históricas, coyunturales, potencialmente infinitos dependiendo de la riqueza social. El snces susceptible de investigación y verificación científica (biológica, antropológica,

\begin{tabular}{|l|l|l|l|l|}
\cline { 2 - 5 } Q & Ano 5 & n.13 & Agosto - Dezembro 2018 & p. 27 - 77 \\
\hline
\end{tabular}


psicológica, histórica, sociológica, etc.). Los aportes de M. Neef(Max-Neef, Elizalde, yHopenhayn, 1992), Martha Nussbaum (Nussbaum, 2016; Nussbaum, Vilá Vernis, y Santos Mosquera, 2012) y Julio Boltvinik(Boltvinik, 2005)nos han ayudado ganar claridad en estos postulados.

Aquí radica una de las grandes diferencias con todas las propuestas idealistas, muchas de ellas nacidas en la tradición iuspositivista. La inquietud que mueve el mundo es una inquietud de energía material. Esta materialidad está transida y se expresa como átomos, como células, tejidos, órganos, cuerpos inquietos por dar de sí, por florecer satisfaciendo su necesidad de comunicación energética con el cosmos. Las ideas creadas por los seres humanos son creaciones de energía corporal (material). Ahora bien, también aquí hay otro gran aporte del iusmaterialismo para evitar el desliz historicista de alguna tradición marxista y no marxista. El snces una constante histórica. Es ciertamente histórico, pero permanece constante en la especie mientras no haya un cambio de la misma. El iusmaterialismo elude el error de afirmar con ambigüedad y sin precisión que las necesidades como son históricas cambian de una época a otra, de un sujeto a otro. Se llega con ello al absurdo de afirmar que hoy los seres humanos tenemos la necesidad de transportarnos (comunicación) para vivir pero que ayer tal vez no. ¿Acaso ha ocurrido esto en los doscientos mil años de existencia de nuestra especie? El grado (el umbral), la urgencia, el modo histórico de satisfacción es una evidencia que cambia históricamente. Sin embargo, es un error confundir historicidad cultural de los "satisfactores" con la constante histórica del snc. La riqueza de la humanidad ha creado el carro, el barco, el tren,el auto, los aviones, etc., como satisfactores de la necesidad de comunicación (transporte). Satisfactores diversos y plurales pero una común necesidad/capacidad. Aquí está el fundamento material histórico de la complementariedad dialéctica entre la unidad y la diversidad. Y aquí está también la diferencia total con el dualismo metafísico presente en iusnaturalismo e iuspositivismo que les hace coincidir en la creencia de que hay necesidades básicas y no básicas. Lo que nos aclara el iusmaterialismo es que existe un solo sistema integrado de necesidades/capacidades. La urgencia histórica concreta de satisfacción de una sobre otra para asegurar la vida es lo que temporalmente dota a una de jerarquía sobre las otras en la satisfacción.

\begin{tabular}{|l|l|l|l|l|}
\cline { 2 - 5 } Q Qovista Dialectus & Ano 5 & n.13 & Agosto - Dezembro 2018 & p. 27 - 77 \\
\hline
\end{tabular}




\section{FILOSOFÍA JURÍDICA LATINO AMERICANA EN EL SIGLO XXI...}

Antonio Salamanca

Como la praxis no es una estructura sin carne, aquellase expresa en la estructura del snc. A modo de postulado explicativo (sometido a verificación), el iusmaterialismo encuentra que la vida es un sistema de tres necesidades/capacidades estructurantes: 1) necesidad/capacidad de volición ejecutiva; 2) necesidad/capacidad de comunicación sentiente; 3 ) necesidad/capacidad de aprehensión cognitiva. Cada una de ellas se desagrega a su vez en tres, que se corresponden con las que hemos indicado en la estructura de la praxis. El iusmaterialismo postula que nueve son las necesidades/capacidades estructurantes de la praxis vital en el homo sapiens sapiens. De estas nueve se desagregan otras más que pueden ser precisadas también en número finito. En Teoría socialista del derecho (2011) hemos propuesto una desagregación.

Como hemos indicado arriba, es esta complementariedad dialéctica entre la unidad del snc y la diversidad de sus satisfactores históricos la que posibilita al iusmaterialismo:ser un paradigma jurídico esencialmente intercultural (transcultural); el diálogo crítico decolonial; la superación del etnocentrismo, del patriarcalismo, etc. Es esta materialidad (contenido) del sncla que ofrece una estructura integrada al sistema de derechos humanos de los pueblos y derechos de la naturaleza. Es el motor, la inquietud histórica que ha puesto en marcha las luchas sociales por los derechos humanos. Es la materialidad que permite la universalización de los derechos humanos desde abajo en diálogo intercultural.

$4^{\circ}$.La moralidad estructural radical ineludible de la praxis es unacondición cosustantiva de toda acción concretapor su afectación a la vida o la muerte de los pueblos y la Naturaleza. La materialidad de la praxis vital del snc es constitutivamente moral. Moral por el carácter bivalente que tiene toda acción del homo sapiens sapiens respecto a la vida o muerte propia, de los pueblos y la naturaleza. La moralidad material del dinamismo histórico de la praxis es la fuente de la legitimidad moral de las religiones y filosofías así como de las posibilidades de una comunicación en diálogo ecuménico e interreligioso. La moralidad material de la praxis abarca la razón, la consciencia y la dimensión biológica de la existencia. La materialidad de la moral es más amplia que la reducción al ámbito de la madurez racional responsable (de la razón); más amplia que la consciencia (sea esta racional o no). La materialidad de la moralidad la hace tener también una dimensión física, química, biológica e inconsciente. El iusmaterialismo asume el carácter inescapable binario de la opción por la

\begin{tabular}{|l|l|l|l|l|}
\cline { 2 - 5 } Q Qovista Dialectus & Ano 5 & n.13 & Agosto - Dezembro 2018 & p. 27 - 77 \\
\hline
\end{tabular}


vida o la muerte en cada opción y acción. La opción por la vida, por la producción, reproducción y florecimiento de la vida de los pueblos y la naturaleza en cada acción es una de las posibilidades. La acción que apuesta por la vida, tan moral como la que apuesta por la muerte. Ambas son igualmente morales. Una es la moral por la vida, que permite la continuidad y el florecimiento. La otra, es la moral de la muerte, que lleva a la aniquilación de la vida.

Este carácter material e ineludible de la moralidad de la praxis es el que evidencia algunas carencias radicales y la imposibilidad explicativa del positivismo jurídico (más extremo). El derecho es ineludiblemente, radicalmente, un modo de praxis moral. Es imposible elaborar una teoría del derecho sin asentarse en la axiología del sistema del snc. La expresión moral (ética) del snc es el sistema integrado de valores morales para la vida de los pueblos y la naturaleza, en pugna con el sistema de disvalores de muerte. Las prácticas y teorías que mejor entiende la ética o moral iusmaterialista de la vida son las propuestas éticas humanistas (E. Fromm), éticas del diálogo intercultural (R. Fornet-Betancourt), del cuidado (C. Gilligan), de la responsabilidad (H. Jonas), de la liberación (E. Dussel),ecocomunitarias (S. López), de la ecología social (L. Boff, J. Lovelock), de la revolución. La axiología iusmaterialista es biológica (más que ontológica). Es otra cosa que el objetivismo moral de las buenas razones para la acción postulado en algunas propuestas que se consideran postpositivistas. Para M. Atienza, “...la objetividad moral es, por así decirlo, una objetividad de razones (una objetividad no ontológica), pero esas razones objetivas son tanto procedimentales como sustantivas. Y, por otro lado, la vía de la fundamentación procedimental de la ética y la vía sustantiva se complementan: esas necesidades o capacidades podrían verse como el resultado de un procedimiento de discusión racional; pero el diálogo racional presupone también que quienes participan en el mismo son individuos a los que no se niega sus capacidades básicas”(Atienza, 2017, p. 216).

Otras de las grandes diferencias que tiene el iusmaterialismo con el positivismo jurídico es que legitima la praxis jurídica en la praxis moral por la vida. Entiende los valores morales no como principios abstractos o palabras de alguna divinidad, sino como la carga para la vida o la muerte que tienen las acciones en su poder real de satisfacción o insatisfacción del snc.Además, también otro aporte fundamental es que el sistema de valores

\begin{tabular}{|c|c|c|c|c|}
\hline Qevista Dialectus & Ano 5 & n.13 & Agosto - Dezembro 2018 & p. $27-77$ \\
\hline
\end{tabular}




\section{FILOSOFÍA JURÍDICA LATINO AMERICANA EN EL SIGLO XXI...}

Antonio Salamanca

es un sistema axiológico integrado. El sistema axiológico no es un sistema inconexo de valores morales, dualista ohilemórfica.Es un todo integrado, donde no cabe hablar de valores primarios vs superiores; materiales vs espirituales. El dualismo axiológico — que se funda en el dualismo metafísico que diferencia entre necesidades básicas (del cuerpo)vs no básicas (el espíritu) - se puede evidenciar incluso entre aquellos quienes apuestan por un objetivismo moral mínimo como M. Atienza: “[p]ero ser objetivista no significa —o no significa necesariamente - ser realista moral. Se puede muy bien pensar que los valores son propiedades que atribuimos a ciertas acciones y estados de cosas, pero no de manera arbitraria, sino porque satisfacen necesidades básicas de los individuos o les proveen de capacidades indispensables para desarrollar una vida buena"(Atienza, 2017, p. 138).

$5^{\circ}$. La dimensión ineludible político-institucional de la praxis.El derecho de los oprimidos y de la naturaleza es una praxis constitutivamente política. La materialidad histórica de la praxis vital además de moral es esencialmente político-institucional. La praxis política es una modalidad de la praxis moral. La praxis no es primariamente de un individuo aislado, sumado a otro individuo aislado. La praxis vital es históricamente una praxis filogenética comunitaria. La praxis es "co-praxis" propiamente. La vida del homo sapiens sapiens siempre es "covida". Es posible el "yo" por el "nosotros" de la especie.Es por esa razón que el dinamismo histórico de la praxis es estructuralmente "político". Y la praxis política es asimismo esencialmente institucional. La institucionalidad ha acompañado a la especie humana desde sus orígenes. Con un menor o mayor grado de complejidad, siempre han necesitado "estructura organizativa" para sus vidas. Tenemos un abanico amplio de instituciones que van desde los ritos de caza y pesca de los forrajeros nómadas, hasta las edificaciones hidráulicas de culturas agrícolas. Los pueblos, desde la noche de los tiempos, por muy sencilla que haya sido su institucionalidad, han necesitado y no pueden escapar desus organizaciones, de sus ritos, de sus convenciones, para vivir.

Podemos coincidir en que el Estado es la institucionalidad de la vida comunitaria de un pueblo con la naturaleza, en un territorio con límites estables o cambiantes. Si compartimos esto, el iusmaterialismo, y aquí una diferencia con el anarquismo y cierto marxismo, no es anarquista, sino que se compromete con la lucha por la creación de instituciones públicas al servicio de la satisfacción del snc. Apuesta por un sistema político-

\begin{tabular}{|l|l|l|l|l|}
\cline { 2 - 5 } Q Qovista Dialectus & Ano 5 & n.13 & Agosto - Dezembro 2018 & p. 27 - 77 \\
\hline
\end{tabular}


institucional (estado) que garantice la vida de los pueblos y la naturaleza, su producción, reproducción y florecimiento; al tiempo que combate la institucionalidad de "pseudoestados" criminales o mafiosos (el estado criminal capitalista es un ejemplo). Más allá de etiquetas, pero pensando en el contenido, el iusmaterialismoencuentra este proyecto político no capitalista, en el verdadero socialismo (comunismo). El contenido del proyecto políticoinstitucional iusmaterialista es el sistema de derechos humanos de los pueblos y la naturaleza. Este proyecto no es el discurso generacional burgués de derechos humanos, sino el proyecto jurídico político del sistema de derechos humanos de los pueblos y la naturaleza, como lo entiende el iusmaterialismo.

$6^{\circ}$. La expresión histórica de la praxis político moral como praxis jurídica. El iusmaterialismo postula que los derechos deos pueblos y la naturaleza, que el derecho, es una praxis con poder real, es una relación social de poder. Pero no de la bivalencia del poder como violencia (para la muerte), sino de la bivalencia del poder como fuerza (para la vida). Aquí reside una de las diferencias fundamentales con el iusnaturalismo. Este poder potencial que tiene la persona individualmente considerada y como pueblo no es un poder "potencial", sino un poder "real". Para que este poder sea real se necesita medios materiales (institucionales, comunitarios, políticas públicas etc.), para que las personas, los pueblos y la naturaleza puedan decidir, o exigir cuando consideren, la satisfacción del bien jurídico que la comunidad ha positivado de forma autónoma como derecho. El iusnaturalismo ha afirmado que existen derechos naturales, que los seres humanos nacemos con derechos innatos. Y no es así. Nacemos con nuestro snc, para poder tener derecho(s) necesitamos el poder real, y esto no es innato ni nos viene por naturaleza, es un "empoderamiento con la fuerza comunitaria".El carácter o modalidad jurídica de la praxis se lo otorga una triple condición: a) el direccionamiento del poder de la materialidad de la praxis para generar, reproducir y florecer la vida de los pueblos y la naturaleza. Esto es, para la satisfacción de necesidades/capacidades (contenido material de la justicia); b) que han sido identificadas y acotadas por la comunidad, de forma autónoma, como especialmente relevantes para la vida, y por tanto, merecedoras de una empoderamiento especial comunitario; c) la especialidad de esa protección es contar con el apoyo tutelar del poder de la fuerza (no la violencia) coactiva de la comunidad. Aquí está también otro de los aportes del iusmaterialismo a cier-

\begin{tabular}{|l|l|l|l|l|}
\cline { 2 - 5 } Q & Ano 5 & n.13 & Agosto - Dezembro 2018 & p. 27 - 77 \\
\hline
\end{tabular}




\section{FILOSOFÍA JURÍDICA LATINO AMERICANA EN EL SIGLO XXI...}

\section{Antonio Salamanca}

ta tradición marxista que identifica el derecho con una supraestructura de dominio burguesa que tendrá que desaparecer. Eso es cierto del derecho burgués, pero el derecho consuetudinario de los pobres y oprimidos no es un derecho burgués, sino un bien imprescindible e ineludible para toda sociedad. Haciendo esta distinción entre derecho y contraderecho, el iusmaterialismo es más radical respecto al primero de lo que considera M. Atienza, cuando afirma que: “[e]l Derecho, en definitiva (o, matizándolo más: ciertos aspectos del ciertos tipos de Derecho), no tiene(n) solo un valor instrumental, sino final; y, por eso, no es un mal necesario, sino también (si se quiere: en parte, limitadamente) un bien”(Atienza, 2017, p. 309).

$7^{\circ}$. La existencia histórica delderecho, de los derechos de los pueblos y la naturaleza, es como derecho a la revolución. El modo de expresarse el derecho a la vida (madre de todos los derechos) históricamente situado es como praxis político-jurídica revolucionaria. El modo de existir el derecho en la historia tieneuna doble ocupación: a) encauzando la praxis social y particular con la brújula de la vida (de la justicia); b) subvirtiendo las situaciones de injusticia y reencauzándolas hacia la vida(Davidson, Fontana y Madariaga, 2013). Esta doble ocupación es el contenido histórico del derecho a la revolución(Salamanca, 2006). Un derecho nodriza que no es un acto (esto puede ser un momento del proceso revolucionario). El derecho a la revolución es el proceso históricode poner el mundo del derecho cuando está del revés(Pontón, 2016). Es crear vida cuando hay muerte. Esta dimensión es otra de las diferencias fundamentales con el paradigma iusnaturalista y con el iuspositivismo. Ambos se han construido de espaldas a los saberes jurídicos de los pueblos. Por eso es que M. Atienza constata: “[e]n todo caso...., es cierto que la teoría del Derecho contemporáneo....se ha construido demasiado a espaldas de los saberes sociales sobre el Derecho, y que eso ha llevado también a que se desentendiera de la transformación social."(Atienza, 2017, p. 280). Las estrategias de lucha del derecho a la revolución son varias, aunque la más radical y fecunda es el derecho a la revolución: a) positivismo jurídico de combate; b) hermenéutica judicial alternativa; c) derecho insurgente. Para Wolkmer, "el Derecho insurgente" es la modalidad más auténtica y genuina de juridicidad alternativa..." (Wolkmer, 2017, p. 190).

\begin{tabular}{|c|c|c|c|c|}
\cline { 2 - 5 } & Ano 5 & n.13 & Agosto-Dezembro 2018 & p. $27-77$ \\
\hline
\end{tabular}


Es el Derecho paralelo, vivo y comunitario que emerge permanentemente de los intereses y necesidades de la sociedad. Es la creación y el reconocimiento de derechos fundamentales (derecho a la vida, a la libertad, a los sobrevivencia, etc.) engendrados en los conflictos y en las luchas de grupos sociales, pudiendo coexistir u oponerse a las leyes elaboradas por la actividad estatal. Se trata de otra legalidad que no se ajusta necesariamente al derecho convencional vigente, pudiendo ser visto como un "nuevo" derecho surgido en el espacio de manifestaciones sociales plurales o de comunidades autonómicas (Wolkmer, 2017, p. 189190).

\section{III._Y por qué el iusmaterialismo puede decir eso del derecho?}

Hay unos senderos (agujeros) epistemológicos y ontológicos que permiten adentrarse en este emocionante mundo(s) y ver y decir el derecho así,como Alicia en el país de las maravillas. Estas ventanas (agujeros) son:

$\left.1^{a}\right)$ La aprehensión cognitiva (y también racional) de la realidaddel mundo (cosmos) es posible para el homo sapiens sapiens (si no es que también sea posible para todo ser vivo). Hay una salida del laberinto del escepticismo cognitivo, respecto a las posibilidades del conocimiento (también el jurídico), que tiene perdidos a muchos. La brújula humilde del método científico orienta con seguridad hacia la verdad (también jurídica).La realidad no es el resultado de una conexión mental en la mente del sujeto de un infinito número de impresiones aisladas, sino una aprehensión de realidad sucesiva en la que va la causalidad que permite descubrir la causación. El materialismo histórico marxista y el realismo sentiente de la obra de X. Zubiri (su trilogía) son indagaciones fundamentales para que los pueblos no se pierdan en el laberinto del escepticismo cognitivo, que tiene colonizada la mayor parte de las ciencias sociales y humanas. En el campo jurídico también el escepticismo cognitivo se ha propagado, incluso en el pensamiento jurídico crítico. Por ejemplo, para Boaventura, su concepción delderecho no sale del laberinto de la tradición escéptica cognitiva: "[s]iguiendo la literatura antropológica jurídica y la filosofía del derecho antipositivista de comienzos del siglo $\mathrm{XX}$, concibo el derecho como un cuerpo de procedimientos regularizados y estándares normativos que se considera exigible — es decir, susceptible de serimpuesto por una autoridad judicial — en un grupo determinado y que contribuye a la creación, prevención y resolución de disputas a través de discursos argumentativos unidos a la amenaza de la fuerza"(citado en Atienza, 2017, p. 311). En esta concepción delderecho se evidencia las limitaciones del escepticismo cognitivo. Como muestra M.

\begin{tabular}{|l|l|l|l|l|}
\cline { 2 - 5 } Q & Ano 5 & n.13 & Agosto - Dezembro 2018 & p. 27 - 77 \\
\hline
\end{tabular}


Atienza, la obra de Santos muestra “...cierta tendencia...al antirracionalismo y a sostener versiones fuertes de escepticismo epistemológico y de relativismo cultural"(Atienza, 2017, p. 319). Queda limitado por una concepción de la ciencia propia del "convencionalismo o constructivismo epistemológico que "fabrica los hechos"(Atienza, 2017, p. 320).

$\left.2^{a}\right)$ Existe un sendero que evita el desvío de los callejones del realismo ingenuo y del idealismo. Ese sendero es la gnoseología y ontología materialista. El 'ser' es un modo de realidad material. La realidad no es un modo de ser. El 'ser' no tiene sustantividad material, sino la realidad. El 'ser' depende de la realidad. Las cosas materiales son sustantividades materiales, no sustancias compuestas de materia y forma (hilemórficas). El mundo no es la síntesis racional de lo categorial y lo fenoménico, sino la aprehensión de realidad en cuanto una unidad en la praxis misma. El Espíritu Absoluto no es el contenido ontológico de la realidad, ni 'la razón lógica es lo sustancial a lo real'. Por el contrario, es la realidad material, como hecho, y no la dialéctica del espíritu absoluto, como idea, lo que da o quita razón a la praxis de vida de los pueblos y la naturaleza.

En el campo jurídico, desde la misma tradición que identificamos positivista, y

que M. Atienza denomina postpositivista, se asume ya las limitaciones del reduccionismo normativista, también incluso en el modo en que disciplinas como la sociología entiende al derecho. Coincidiendo con M. Atienza, el derecho, antes que norma es praxis social, una diferencia que él consideraontológica. Diferencia mucho más profunda que un simple cambio de perspectiva. Para él, la concepción del derecho como praxis social y vinculada con la moral la encuentra en la obra de R. Ihering, y se hace eco de su definición exhaustiva delderecho: "El Derecho es el conjunto de las condiciones de vida de la sociedad en el sentido más ampliode la palabra, asegurado mediante la coacción externa por el poder público" (Atienza, 2017, p. 34). En la línea de Ihering, M. Atienza ofrece su concepto dederecho sustantivo: “...el derecho (o mejor, la idea regulativa del Derecho) podría definirse, remedando a Ihering, como el conjunto de las condiciones de vida dela sociedad que satisfacen los derechos fundamentales basados en la dignidad humana, aseguradas esas condiciones mediante la coacción externa por un poder público ejercido de acuerdo con los requerimientos del Estado de Derecho.”(Atienza, 2017, pp. 45-46).

\begin{tabular}{|c|c|c|c|c|}
\cline { 2 - 5 } & Ano 5 & n.13 & Agosto-Dezembro 2018 & p. $27-77$ \\
\hline
\end{tabular}


Y, para despejar equívocos desde el comienzo, conviene dejar claro que la consideración del derecho como una actividad o práctica social no supone desconocer que el Derecho es también un sistema de normas; mejor, que las normas forman parte de esa práctica. En lo que se pretende poner el acento es en la insuficiencia de una concepción meramente normativista del Derecho; lo que se niega es que a partir del entendimiento del Derecho como un sistema de normas pueda darse cuenta adecuadamente de toda la realidad jurídica, puede comprenderse cabalmente en qué consiste el Derecho(Atienza, 2017, p. 17).

$3^{\mathrm{a})}$ El movimiento histórico lo es siempre de la sustantividad de una acción (praxis) material. El movimiento histórico de los pueblos no reposa sobre sí mismo. No hay movimiento histórico sin sustantividad estructural moviente. La praxis material es la sustantividad del movimiento histórico. El historicismo es un error porque entiende posible el movimiento sin sustantividad o diluye la sustantividad en movimiento. "Caminante, no hay camino, se hace camino al andar", se dice. Sin embargo, el camino, en el sentido de decurso humano implícito en el verso de Antonio Machado, requiere un cuerpo, piernas y tierra para andar. Este sendero es una de las principales diferencias con corrientes de pensamiento jurídico crítico que siguen asumiendo el desliz historicista. Por ejemplo, A. C. Wolkmer mantiene las limitaciones historicistas y dualistas respecto al sistema de necesidades: "cabe considerar también los procesos de lucha por la constitución de las necesidades humanas y su justa satisfacción como criterio para pensar nuevas formas de legitimación en el ámbito de la normatividad y regulación social...Por ser inagotables e ilimitadas en el tiempo y en el espacio, las necesidades humanas están en permanente desarrollo y creación. El conjunto de necesidades humanas varía de una sociedad o cultura a otra, incluyendo un amplio y complejo proceso de socialización”(Wolkmer, 2017, p. 226).

$\left.4^{a}\right)$ La satisfacción del sistema integrado de necesidades/capacidades para la producción, reproducción y florecimiento de la vida de los pueblos y la naturaleza es el motor de la historia. Esta insatisfacción y la búsqueda de satisfacción es la fuente última de la "inquietud" que mueve al mundo de la vida. El motor último que mueve a los pueblos no es la tensión bipolar placer/dolor, sino que el placer/dolor, como síntoma, está siempre referido a la vida/muerte de los pueblos y la naturaleza. No es el discurso subjetivo o intersubjetivo, este reposa en la sustantividad de quienes ponen la carne y la sangre a las palabras. Tampoco es la voluntad de vida el motor de la realidad ni el punto de arranque epistemológico del conocimiento, sino que la voluntad de vida lo es siempre de algo que le sustenta a

\begin{tabular}{|l|l|l|l|l|}
\cline { 2 - 5 } Q Rovista Dialectus & Ano 5 & n.13 & Agosto - Dezembro 2018 & p. 27 - 77 \\
\hline
\end{tabular}


la voluntad, que tiene sustantividad: la praxis material de la vida de los pueblos y la naturaleza. Además de voluntad, es afección sentiente y aprehensión intelectiva. Los tres son los momentos estructurantes y fundantes de la praxis material de la vida de los pueblos. La lucha de clases, como motor de la historia en el marxismo tiene aquí un fundamento último. Existe lucha de clases en la historia porque hay grupos sociales que impiden a otros la satisfacción de sus necesidades y el florecimiento de sus capacidades.Es la búsqueda de satisfacción del sistema integrado de necesidades/capacidades el motor del movimiento histórico de la praxis de los pueblos.

Es este hecho el que permite entender a los derechos humanos como las luchas históricas de los movimientos sociales. Los derechos humanos, su fundamentación en el paradigma burgués donde ha nacido su formulación, arrastran fuertes limitaciones y no explican con coherencia qué son. Entre algunas de esas limitaciones: individualismo, abstracción, formalismo, estatismo y eurocentrismo (Wolkmer, 2017, p. 118). Como alternativa, hoy algunos autores, como Dalmo de Abreu Dallari que entienden los derechos humanos en relación a "las necesidades esenciales de la persona humana" que "deben ser atendidas igualmente para que todas puedan vivir con dignidad" (Wolkmer, 2017, p. 118). Es este motor de la historia el que puede permitir el reclamo de A. C. Wolkmerpor un "universalismo de llegada" o, en expresión de J. Herrera Flores, "una racionalidad que no niega que es posible llegar a una síntesis universal de las diferentes opciones relativas a los derechos" (Wolkmer, 2017, p. 118). Desde la interculturalidad, se entiende a los derechos humanos "resultantes de los procesos de luchas sociales colectivas, que buscan construir espacios para la realización de las necesidades básicas y para una vida humana con más dignidad” (Wolkmer, 2017, p. 118).

$5^{\text {a) }}$ La realidad es aprehendida como inescapablemente debitoria para el homo sapiens sapiens. Es posible salir del laberinto de la falacia naturalista, hegemónica hoy, que ha perdido la moral en el positivismo (también jurídico).La sustantividad es debitoria. La dimensión axiológica de la realidad es ineludible. Esa dimensión de la praxis es constitutiva. El deber ser está en la realidad y se puede conocer. El escepticismo axiológico es una deriva del escepticismo cognitivo. La superación de esta limitación incluso hoy está siendo demanda, aunque con problema en encontrar el sendero, por autores como M. Atienza des-

\begin{tabular}{|c|c|c|c|c|}
\cline { 2 - 5 } & Ano 5 & n.13 & Agosto-Dezembro 2018 & p. $27-77$ \\
\hline
\end{tabular}


de la tradición analítico-argumentativa: “[L]a ideología de la separación (entre el Derecho y la moral, pero también entre el ser y el deber ser, entre los hechos y los valores) es, me parece, el elemento más característico del positivismo jurídico (como lo señalaba Comanducci) y también su talón de Aquiles: lo que lo vuelve una concepción del Derecho incapaz de dar cuenta de toda la riqueza que envuelve esa práctica”(Atienza, 2017, p. 217) ¿quiere ello decir que también habría que considerar como convencionales las necesidades humanas?(Atienza, 2017, p. 305). Ahora bien, el carácter debitorio de la realidad y la posibilidad de la aprehensión axiológica de la misma abre un horizonte mucho más amplio que el aún “escéptico" objetivismo moral en las propuestas de objetivismo moral de algunos que como M. Atienza se consideran postpositivistas.

En la propuesta de M. Atienza, “[e]lpostpositivismo no significa por ello la vuelta al Derecho natural, no niega el carácter "artificial”, social e histórico del Derecho (esa vendría a ser, de acuerdo con González Vicén, la tesis central de todas las teorías iuspositivistas: concebir el Derecho como una realidad social e histórica), pero sí la tesis de la separación metodológica o conceptual entre el Derecho y la moral; mejor aún, no niega que desde ciertas perspectivas sea posible (necesario) distinguir entre el Derecho y la moral, pero insiste en que esa separación no puede verse en términos dicotómicos, o sea, entre el Derecho y la moral hay tanto separación como continuidad: son "conceptos conjugados"''(Atienza, 2017, p. 10).La apuesta de M. Atienza es el objetivismo moral. Sus postulados o tesis son: 1) el objetivismo moral no significa necesariamente realismo moral, sino que es más bien una objetividad de las razones; 2) la objetividad se predica tanto de las normas como de los valores; 3) el valor de la tolerancia no está legado con el relativismo moral, sino con el objetivismo; 4) las razones del objetivismo moral son tanto procedimientales como sustantivas; 5) una teoría delderecho que pretenda dar cuenta cabalmente de las prácticas jurídicas necesita asumir el objetivismo moral (Atienza, 2017, p. 12).

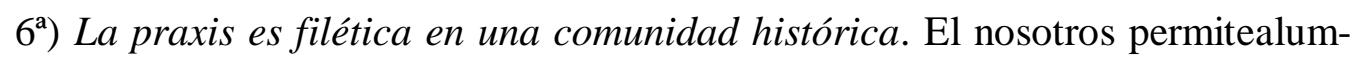
brar la identidad personal. El sujeto pensante racional individual esuna posibilitación de la praxis de la vida humana de los pueblos y la naturaleza.El yo solo es posible en el nosotros. El individualismo ideológico no se sostiene antropológicamente. La tradición iusmaterialista es colectiva, los derechos no son de individuos aislados que deciden ponerse de acuerdo,

\begin{tabular}{|c|c|c|c|c|}
\cline { 2 - 5 } & Ano 5 & n.13 & Agosto-Dezembro 2018 & p. $27-77$ \\
\hline
\end{tabular}


sino de comunidades que permiten el florecimiento personal de sus miembros y de la naturaleza. Los derechos colectivos permiten los llamados derechos personales.

$\left.7^{\mathrm{a}}\right)$ La cultura y el lenguaje lo son de la sustantividad material de la praxis. La cultura de los pueblos, entendida como creaciones artísticas, ideológicas,filosóficas y jurídicas, reside y es expresión de una sustantividadque ella no tiene per se: la crianza, el cultivode la vida de los pueblos y la naturaleza. ¿Qué esla cultura de los pueblos como creaciones ideales, sin los cerebros, corazones y cuerpos, sin las manos y la tierra que la crean? La filosofía jurídica intercultural y decolonial podrá serlo si es iusmaterialista, de otro modo quedará perdida en el laberinto del voluntarismo idealista intersubjetivo, creador de espectros. El lenguaje ciertamente es una significación, pero lo es como reducción de una dimensión signante más amplia; y ambas son posibles porque se asientan en un estrato mayor: la dimensión expresiva de la materialidad de la vida. Hay un interlocutor por mucho tiempo desconocido, silenciado y relegado en las comunidades de discursos: el "de suyo" de la realidad. ¡Ecuchémosle! ¡Cuidémosle! ¡Liberémonos en él! (X. Zubiri).

\section{Conclusión}

Los dos grandes paradigmas o tradiciones jurídicas que han colonizado América Latina desde la Conquista europea han sido el iusnaturalismo, hasta el siglo XIX, y desde entonces el iuspositivismo. Ambos han funcionado en términos generales como ideologías jurídicas coloniales de enajenación, indigencia y dominación para los pobres y oprimidos, así como para nuestro planeta. Además de una funciónencubridora y legitimadora del colonialismo mercantilista, primero, y capitalista, después, como filosofías y teorías jurídicas han evidenciado limitaciones dogmáticas en la capacidad explicativa—sin contradicciones-, de lo que sea el derecho de los pueblos y la naturaleza. El positivismo jurídico, hoy la ideología dominante de la burguesía, ha fetichizado el derecho en norma, con poder violento para disciplinar a los humildes y a la Madre Tierra. Sin embargo,aparece impotente para servir a los bienes jurídicos de la vida. La situación real de indigencia jurídica en que viven las grandes mayorías y Gaiaestá estimulando múltiples y pluralesresistencias e

\begin{tabular}{|c|c|c|c|c|}
\cline { 2 - 5 } & Ano 5 & n.13 & Agosto-Dezembro 2018 & p. $27-77$ \\
\hline
\end{tabular}


investigaciones jurídicas críticas con un horizonte: biocéntrico, decolonial, feminista,intercultural, postcapitalista ypostpositivista. Pero las teorías críticas del derecho en nuestra América tienen todavíaun impacto limitado. Y en esta primera década del siglo no van ganando terreno. Por el contrario, lo que se refuerza desde los centros de producción ideológica ( $v . g r$. facultades de derecho, etc.) es la alienación (expropiación) jurídica. Es por esta razón que urge continuar y radicalizar la lucha jurídica contrahegemónica para empoderarnos jurídicamente; recuperar algo que fue y es de los pueblos: la conciencia y el poder real de los derechos en nuestras manos.En ello, la lucha filosófica-teórica (ideológica) es fundamental. El pensamiento jurídico crítico del siglo XXI en América Latina, si quiere serbiocéntrico, decolonial, feminista, intercultural, postcapitalista y postpositivista no podrá hacerlo en el laberinto del postmodernismo deconstructivo nihilista, timorato y alérgico a los metarrelatos transformadores. Necesita ser mucho más radical (materialmente transmoderno). En su éxodo, además de audacia y valentía,necesita cruzar el desierto sin perderse con los espejismos propios del idealismo, del dualismo metafísico,del escepticismo y relativismo cognitivo y moral, de las derivas historicistas que terminan de nuevo en idealismo hegeliano y del dogmatismo.La esperanza cimarrona que nos anima es que la tierra prometida la hemos conocido en el pasado, nos sacaron de ella.Yno estamos solos:contamos con los pobres y explotados como compañeros de viaje; con sus derechos consuetudinarios; con los sistemas jurídicos milenarios de sus pueblos; con sus sabiduríasinvisibilizadas, ninguneadasy despreciadas por los poderosos. En susurro revolucionariopronuncian su nombre: iusmaterialismo.

\section{Referencias}

Arango Rivadeneira, R. (2008). Derechos humanos como límite a la democracia: análisis de la ley de justicia y paz. Bogotá: Grupo Editorial Norma.

Atienza, M. (2017). Filosofía del derecho y transformación social. Madrid: Trotta.

Beuchot, M., y González, J. E. (2018). Diversidad y diálogo intercultural. Bogotá: El Búho.

Bilbeny, N. (2015). Justicia compasiva: la justicia como cuidado de la existencia. Madrid: Tecnos.

\begin{tabular}{|c|c|c|c|c|}
\cline { 2 - 5 } & Ano 5 & n.13 & Agosto-Dezembro 2018 & p. $27-77$ \\
\hline
\end{tabular}


Boltvinik, J. (2005). Ampliar la mirada. Un nuevo enfoque de la pobreza y el florecimiento humano, vol. I[Tesis doctoral] México. Guadalajara, Estado de Jalisco: Centro de Investigaciones y Estudios Superiores en Antropología Social-Occidente.

Davidson, N., Fontana, J., y Madariaga, J. (2013). Transformar el mundo: revoluciones burguesas y revolución social. Barcelona: Pasado \& Presente.

De la Torre Rangel, J. A. (1986). El derecho que nace del pueblo. Aguascalientes: Centro de Investigaciones Regionales de Aguascalientes.

(2004). Hermenéutica analógica: derecho y derechos humanos. Aguascalientes:

Universidad Autónoma de Aguascalientes.

Gabriel, M. (2014). Amor y Capital. Barcelona: El Viejo Topo.

Gargarella, R. (2010). Una maquinaria exhausta: Constitucionalismo y alienación legal en América. Isonomía, (33), 7-34.

Lovelock, J. E. (2007). La venganza de la tierra: la teoría de Gaia y el futuro de la humanidad. México: Planeta.

Lyra Filho, R. (1983a). Karl, meu amigo: diálogo com Marx sobre o direito. Porto Alegre: Fabris Editor. , (1983b). Humanismo Dialéctico. Direito\&Aversso, 3, 19-103.

Marx, K. (2007). Los debates de la Dieta Renana. Barcelona: Gedisa.

Moncayo, V. M., y Rojas, F. (1978). Luchas obreras y política laboral en Colombia. Bogotá: La carreta.

Monreal, E. N. (1980). El derecho como obstáculo al cambio social. Bogotá: Siglo XXI.

Nussbaum, M. C. (2016). Crear capacidades: propuesta para el desarrollo humano. Barcelona: Paidós.

Nussbaum, M. C., Vilá Vernis, R., y Santos Mosquera, A. (2016). Las fronteras de la justicia. Barcelona: Paidós.

Plastino, C. A. (1984). Crítica do direito e do Estado. Rio de Janeiro: Graal.

Pontón, G. (2016). La lucha por la desigualdad: una historia del mundo occidental en el siglo XVIII. Barcelona: Pasado y Presente.

Ribas Alba, J. M. (2015). Prehistoria del derecho. Córdoba: Almuzara.

\begin{tabular}{|c|c|c|c|c|}
\cline { 2 - 4 } Govista & Ano 5 & n.13 & Agosto - Dezembro 2018 & p. $27-77$ \\
\hline
\end{tabular}


Rojas, F. (1977). Criminalidad y constituyente. Bogotá: Cinep.

Rosillo, A. (2012). La tradición hispanoamericana de derechos humanos. Quito: CEDEC.

Salamanca Serrano, A. (2003). Fundamentos de los derechos humanos. Madrid: Nueva Utopía.

(2006). El derecho a la revolución: iusmaterialismo para una política crítica. San Luis Potosí: Facultad de Derecho de la Universidad Autónoma de San Luis Potosí.

(2008). Filosofía de la revolución: filosofía para el socialismo en el siglo XXI. San Luis Potosí: UniversidadAutónoma de San Luis Potosí, Facultad de Derecho.

- (2008). Política de la revolución: filosofía para el socialismo en el siglo XXI.San Luis Potosí: Universidad Autónoma de San Luis Potosí, Facultad de Derecho.

( 2011). Teoría socialista del derecho. 2 vols. Quito, Ed. Jurídica del Ecuador.

(2015). La investigación jurídica intercultural e interdisciplinar. Metodología, epistemología, gnoseología y ontología. Redhes: Revista de Derechos Humanos y Estudios Sociales, VII, 14, 59-92.

(2017). El fetiche jurídico del capital: Expansión imperialista de su hegemonía sistémica a través de los estudios de derecho. Problemata: Revista Internacional de Filosofía, 8(Extra 1), 324-402.

Santos, B. de S. (2003). Crítica de la razón indolente: contra el desperdicio de la experiencia. Desclée de Brouwer.

(2009). Sociología jurídica crítica. Madrid: Trotta/ILSA, 2009.

(2018). Las bifurcaciones del orden: revolución, ciudad, campo e indignación. Madrid: Trotta.

Shady Solís, R., y Leyva, C. (Eds.). (2003). La Ciudad Sagrada de Caral-Supe: Los orígenes de la civilización andina y la formación del Estado pristino en el antiguo Peru. Lima: Instituto Nacional de Cultura.

Slater, P. (1978). Origem e significado da Escola de Frankfurt. Rio de Janeiro: Zahar.

Tobón, G. (1998). El carácter ideológico de la filosofía del derecho. Medellín: Señal Editorial.

\begin{tabular}{|c|c|c|c|c|}
\cline { 2 - 5 } Q Qonista Dialectus & Ano 5 & n.13 & Agosto - Dezembro 2018 & p. 27 - 77 \\
\hline
\end{tabular}




\section{FILOSOFÍA JURÍDICA LATINO AMERICANA EN EL SIGLO XXI... Antonio Salamanca}

Vázquez, R. (2012). Filosofía del derecho en Latinoamérica. Doxa: Cuadernos de filosofía del derecho, (35), 833-858.

Wolkmer, Antonio C. (2017). Teoría crítica del derecho desde América Latina. México: Akal.

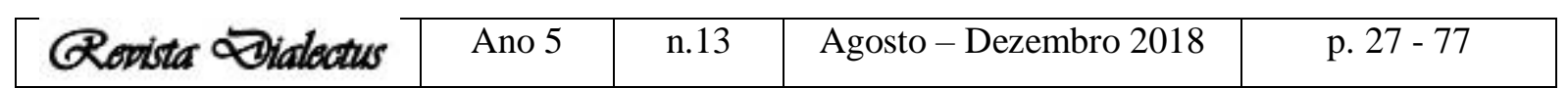

